\title{
Nexus: Agricultura Familiar, Energias Renováveis e Construção de Mercados nos Territórios Rurais do Rio Grande do Norte
}

\author{
Nexus: Family Farming, Renewable Energies and Market Building in \\ Rural Territories in Rio Grande do Norte
}

Elis Regina Monte Feitosa ${ }^{1}$ (D), Emanoel Márcio Nunes ${ }^{1}$ (i), Humberto Dionísio de Andrade ${ }^{2}$ (i), Sergio Schneider ${ }^{3}$ (D), Alexsandra Bezerra da Rocha ${ }^{4}$ (1)

\begin{abstract}
${ }^{1}$ Faculdade de Ciências Econômicas (FACEM), Programa de Pós-graduação em Economia (PPE), Universidade do Estado do Rio Grande do Norte (UERN), Mossoró (RN),Brasil. E-mails: elisrmf@gmail.com; emanoelnunes@uern.br.

${ }^{2}$ Departamento de Engenharia e Tecnologia (DET), Programa de Pós-graduação em Engenharia Elétrica (PPGEE), Universidade Federal Rural do Semi-Árido (UFERSA), Mossoró (RN), Brasil. E-mail: humbertodionisio@ufersa.edu.br.

${ }^{3}$ Instituto de Filosofia e Ciências Humanas (IFCH), Programas de Pós-Graduação em Desenvolvimento Rural (PGDR) e Sociologia (PPGS), Universidade Federal do Rio Grande do Sul (UFRGS), Porto Alegre (RS), Brasil. E-mail: schneide@ufrgs.br. ${ }^{4}$ Centro de Formação de Professores, Universidade Federal de Campina Grande (UFCG), Cajazeiras (PB), Brasil. E-mail: alexsandrarocha2@ufcg.edu.br.
\end{abstract}

\begin{abstract}
Como citar: Feitosa, E.R.M., Nunes, E.M., Andrade, H.D., Schneider, S., Rocha, A.B. (2022). Nexus: agricultura familiar, energias renováveis e construção de mercados nos territórios rurais do Rio Grande do Norte. Revista de Economia e Sociologia Rural, 60(3), e238969. https://doi.org/10.1590/1806-9479.2021.238969
\end{abstract}

Resumo: Este artigo tem como objetivo analisar o Nexus agricultura familiar, energias renováveis e construção de mercados no contexto da dinâmica territorial do RN, particularmente nos territórios Açu-Mossoró, Mato Grande e Sertão Central Cabugi e Litoral Norte. Para isso, foi realizada uma pesquisa exploratória e descritiva, com uma abordagem qualitativa e quantitativa. Foram utilizados dados quantizados da produção de energia renovável, dados econômicos e de mercado para cada território. Utilizaram-se como técnicas de coleta de dados a pesquisa bibliográfica, documental e a pesquisa de campo, através da realização de entrevistas com os gestores das cooperativas de agricultores familiares, contendo pelo menos um representante de cada território avaliado. Como resultados, verificou-se que as contribuições das energias renováveis provenientes de fonte eólica instaladas nessas regiões ainda são incipientes na perspectiva dos gestores das cooperativas, apesar de acreditarem que a apropriação dessa tecnologia pela agricultura familiar poderia contribuir de maneira significativa para a ampliação da produção de alimentos e a construção de mercados

Palavras-chave: agricultura familiar, energias renováveis, cooperativas, territórios.

Abstract: This article aims to analyze the Nexus family farming, renewable energies, and market building in the context of the territorial dynamics of the RN, particularly in the territories Açu-Mossoró, Mato Grande, and Sertão Central Cabugi and Litoral Norte. For this, exploratory and descriptive research was conducted, with a qualitative and quantitative approach. Quantitative data on renewable energy production, economic, and market were used for each territory. Data collection techniques were bibliographic, documentary, and field research, through interviews with the managers of family farmers' cooperatives, containing at least one representative from each evaluated territory. As a result, it was found that the contributions of renewable energy from wind sources installed in these regions are still incipient from the perspective of cooperative managers, although they believe that the appropriation of this technology by family farming could contribute significantly to the expansion of food production and market building.

Keywords: family farming, renewable energy, markets, cooperatives, territories.

\section{Introdução}

Há amplo consenso entre estudiosos de que, devido às tendências transformacionais globais, que passam pelo crescimento populacional, mudanças climáticas e pelo complicado 
gerenciamento de recursos como energia, água e terra, é preciso melhorar a eficiência técnica para que se possa manter os serviços e as infraestruturas que dão guarida ao modelo organizacional das sociedades contemporâneas (Federal Ministry for Economic Cooperation and Development, 2015; Flammini et al., 2017). Sob esta ótica, tomadores de decisão necessitam de ferramentas para poderem estar mais bem informados sobre os trade-offs e as sinergias entre diferentes opções de desenvolvimento e gestão, para ajudá-los a identificar opções sobre como gerenciar recursos de forma sustentável (Flammini et al., 2017). A inter-relação entre água, energia e alimentos avaliada sob a perspectiva do Nexus tem sido considerada uma metodologia inovadora capaz de auxiliar o processo de desenvolvimento sustentável em nível global (International Renewable Energy Agency, 2015; Serraj \& Pingali, 2019).

Diante deste cenário, é importante salientar que o modelo energético baseado nos combustíveis fósseis e na matriz energética predominantemente hidrológica, assim como o seguido pelo Brasil, mostra-se crescentemente inviável e contraditório no momento atual. E isso se deve a um processo mais geral que é o das mudanças climáticas, que afetam não apenas o clima, mas a forma como as economias estão estruturadas. No caso do nordeste do Brasil, bem como nas regiões tropicais do mundo, a escassez de água sempre foi um limitante ao desenvolvimento (Borelli, 2018).

No que concerne ao uso de fósseis, como o petróleo e outros derivados, estudos demonstram que regiões que são dotadas deste recurso em geral padecem da "doença holandesa". Não sem motivo, o estudo de Nunes \& Schneider (2013) mostrou que municípios do Rio Grande do Norte (RN) que dependiam dos royalties do petróleo tinham baixo índice de desenvolvimento humano (IDH). Portanto, emerge um contexto em que recursos abundantes, mas desprestigiados até pouco tempo como o excesso de sol, por exemplo, criam vantagens comparativas naturais em um contexto de mudança climática. Isso leva a indagar sobre as condições e possibilidades de que esta nova matriz de oportunidades de desenvolvimento possa se dar em outras bases do modelo anterior, qual seja, serem menos excludentes social, econômica e ambientalmente mais sustentáveis.

Deste modo, considerando que o Rio Grande do Norte tem ampliado fortemente a produção de energias renováveis, em especial a proveniente de fonte eólica, a principal questão que motivou esta pesquisa foi: qual a potencialidade ou a capacidade de internalização do recurso energia renovável (eólica) pela agricultura familiar e como esse acesso contribui para a ampliação da produção de alimentos e para a construção de mercados? A hipótese é a de que o RN possui uma agricultura familiar ainda frágil e com estrutura de produção econômica precária, apesar do seu potencial para dinamizar a economia do Estado, através da construção e consolidação dos mercados locais e regionais, atrelados à internalização das tecnologias de geração de energia renovável na produção agrícola por meio de organizações coletivas, especialmente as cooperativas da agricultura familiar.

Este artigo tem como objetivo analisar o Nexus entre agricultura familiar, energias renováveis e construção de mercados no contexto da dinâmica territorial do RN, particularmente nos territórios Açu-Mossoró, Mato Grande e Sertão Central Cabugi e Litoral Norte. Trata-se de uma pesquisa de natureza exploratória e descritiva, com uma abordagem qualitativa e quantitativa, que poderá contribuir para a implementação de políticas voltadas para a agricultura familiar e sua inserção nos mercados, ao mesmo tempo em que possibilita compreender a sua relação com a produção de energias renováveis (eólica) no RN, especialmente nos territórios avaliados. Neste sentido, justifica-se a relevância do tema, dada a escassez de pesquisas neste segmento, inclusive para os respectivos territórios. Trata-se de uma pesquisa voltada para o desenvolvimento regional em sua abordagem territorial e local. Tem relevância por extrair 
de pesquisa empírica informações que auxiliam na produção de conhecimento e contribuem para a formulação de políticas públicas.

\section{Referencial teórico}

\subsection{A contribuição da abordagem Nexus}

A preocupação crescente com a escassez de recursos e os impactos das mudanças climáticas que estão ocorrendo ao redor do planeta têm contribuído para a busca de tecnologias capazes de minimizar essas transformações e, ao mesmo tempo, atender à demanda por alimentos, água e energia. Essa é uma perspectiva alinhada com a necessidade de atividades econômicas geradoras de baixo carbono, considerando especialmente as mudanças climáticas em toda a terra. Neste sentido, destacam-se contribuições de autores internacionais, a exemplo de Marsden \& Rucinska (2019), Geels (2014), Tilman et al. (2009), entre outros.

Para Marsden \& Rucinska (2019), existe a preocupação de que até que ponto o mundo tem testemunhado transformações no sentido de uma economia que considere atividades de baixo ou zero carbono, segundo os acordos de Paris da COP21? E, quanto ao Nexus energético/agroalimentar como foco principal, estes autores da universidade de Cardiff apontam que, por um lado, existem tendências contestadas associadas a um 'ock-in'carbonizado, porém, existe o aumento de estratégias e práticas de baixo carbono, por outro.

A preocupação de Geels (2014) vai no sentido da resistência às mudanças fundamentais por parte dos atores do regime econômico ainda baseado no carvão, no petróleo e gás. Este autor, da Universidade de Manchester, introduz política e poder na perspectiva multinível, considerando a resistência e resiliência do regime baseado no carvão, gás e petróleo que insiste em negar os benefícios da ampliação das energias renováveis para atividades geradoras de baixo carbono.

Tilman et al. (2009) apresentaram preocupação semelhante ao propor a análise do trilema alimentos, energia e meio ambiente, com ênfase na produção do que denominou "biocombustíveis benéficos". De acordo com os autores, os biocombustíveis deveriam ser derivados de matérias-primas produzidas com emissões muito mais baixas de gases de efeito estufa do que as do ciclo de vida dos combustíveis fósseis tradicionais e com pouca ou nenhuma competição com a produção de alimentos, o que inclui, por exemplo, o uso de plantas perenes cultivadas em terras degradadas abandonadas do uso agrícola. Nessa análise, o autor coloca em pauta as decisões sobre as terras para a produção de bioenergia, alertando que essas deciões vão muito além do que somente a destinação do uso da terra propriamente dita; elas podem ter impactos globais. Além disso, afirmam que são necessárias melhorias drásticas na política e na tecnologia para reconfigurar a agricultura e o uso da terra para atender à demanda global por matérias-primas para alimentos e biocombustíveis.

Boas políticas públicas garantirão que a produção de biocombustível otimize um conjunto de benefícios, incluindo ganhos reais de energia, redução de gases de efeito estufa, preservação da biodiversidade e manutenção da segurança alimentar (Tilman et al., 2009, p. 271).

$\mathrm{Na}$ análise de Tilman et al. (2009), percebe-se como ponto central a boa gestão de uso da terra como forma de resolver esse trilema alimentos, energia e meio ambiente. Todavia há decisões que envolvem o uso de recursos como a água, por exemplo, com trade-offs que se baseiam em questionamentos como: utilizar a água para gerar energia ou para a produção de alimentos? Além disso, é importante observar que o modelo energético adotado tem grande influência na forma como as sociedades se desenvolvem. Nesse sentido, Urry (2014) analisa 
a forma como as sociedades são "energizadas" e argumenta que a ligação entre a energia proveniente da água e o despotismo indica que os sistemas de energia e os sistemas sociais geralmente estão altamente interconectados. Eles não são independentes, embora as formas em que as sociedades são "energizadas" estejam frequentemente ocultas da observação direta, especialmente no caso de formas de energia maiores e mais distantes. Ademais, na maioria das vezes as pessoas não usam 'energia' como tal, mas obtêm, compram e usam vários bens e serviços. Deste modo, o desenvolvimento da própria sociedade aumenta a demanda por energia, ao passo que adicionais na geração energética incentiva a produção de novos bens e serviços, o que torna o trilema água, energia e meio ambiente ainda mais complexo (Serraj \& Pingali, 2019)

É a partir dessa perspectiva e da necessidade de se pensar na gestão dos recursos de forma integrada que surge a metodologia do Nexus. Essa metodologia sugere uma análise sistêmica das variáveis que contribuem para a avaliação de medidas nos diversos "braços" de estudo, juntamente com os indicadores de sustentabilidade diretamente relevantes para a água, energia e alimentos, é útil contextualizar também o status de sustentabilidade em relação aos recursos humanos. Elas se relacionam com a exigência de intensidade de trabalho, que pode incluir informações sobre salários e emprego, e requisitos de intensidade de capital, que podem incluir informações sobre disponibilidade de capital e custos (Flammini et al., 2017). A figura 1 apresenta a base da metodologia do Nexus.

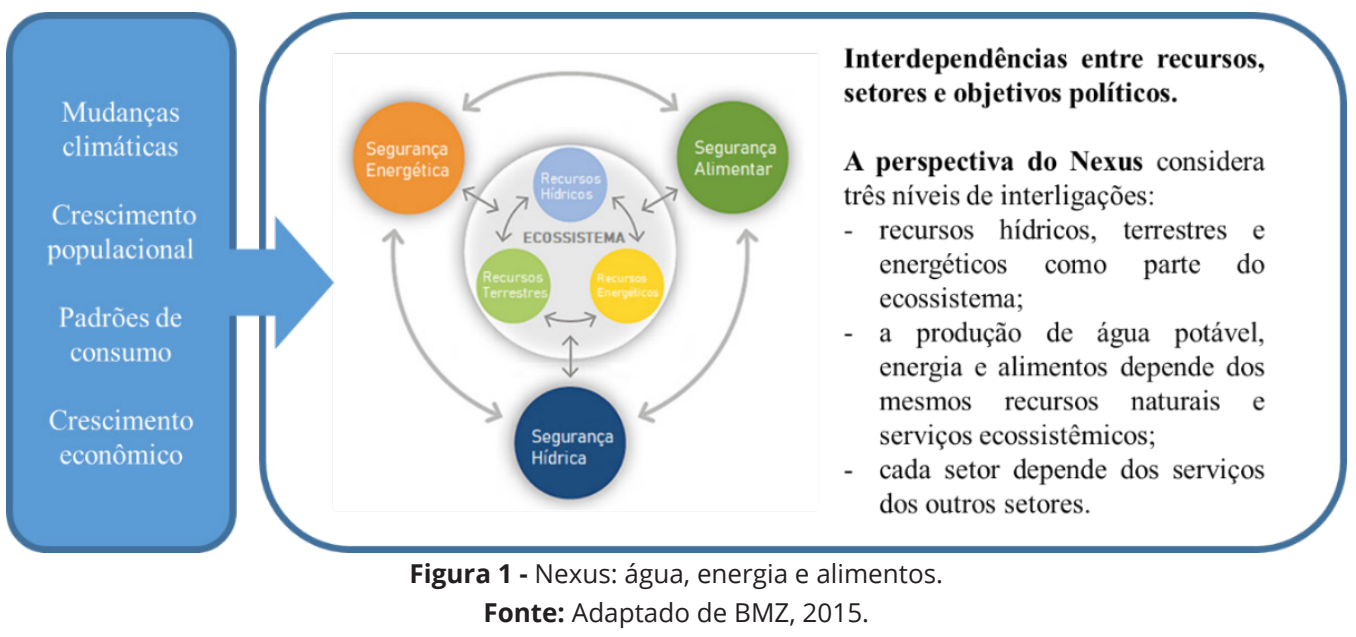

Nesta pesquisa, dado o ambiente em que foi realizada a investigação e a falta de informações sobre gestão dos recursos hídricos para a agricultura familiar, o braço que trata da foi substituído e avaliando-se $o$ aspecto relacionado à construção de mercados, o qual tem grande importância no contexto local e é uma demanda atual. Assim, o Nexus aqui é avaliado sob as perspectivas da agricultura familiar, energias renováveis e construção de mercados.

\subsection{Nexus: Agricultura familiar, energias renováveis e construção de mercados}

A principal relação entre agricultura familiar, energias renováveis e a construção de mercados é caracterizada pela agroenergia. A geração de energia utilizando como matéria-prima produtos agrícolas inclui, mas não está restrita, a produção de biocombustíveis a partir de culturas como a soja, mamona, dendê, girassol e canola (Rambo et al., 2008). 
Neste sentido, um grande incentivo para o aumento da participação dos agricultores familiares nesse mercado foi a implantação do Programa Nacional de Uso e Produção de Biodiesel (PNPB), em dezembro de 2004, pelo governo federal, tendo como objetivo inicial introduzir o biodiesel na matriz energética brasileira, com enfoque na inclusão social e no desenvolvimento regional (Brasil, 2020). Este programa impulsionou a produção agrícola familiar das culturas utilizadas como matéria-prima na produção deste tipo de produto, por diversas regiões no Brasil (Freitas et al., 2017; Da Silva \& Polli, 2020). Assim, por esta análise, há a construção de um novo mercado de consumo para a agricultura familiar, tendo-se o cuidado de respeitar o duplo imperativo de inviolabilidade das florestas naturais e de garantir a segurança alimentar (Sachs, 2007).

Nessa discussão, é importante destacar que a segurança alimentar é uma preocupação mundial e faz parte dos objetivos do desenvolvimento sustentável da Organização das Nações Unidas (ONU), mais precisamente o objetivo $\mathrm{n}^{\circ} 2$ : "Acabar com a fome, alcançar a segurança alimentar e melhoria da nutrição e promover a agricultura sustentável". Além disso, a promoção de uma agricultura sustentável também faz parte desse mesmo pacote, o que inspirou em países como o Brasil, conforme Nunes et al. (2018), a criação e ampliação de políticas com foco na demanda, a exemplo do Programa de Aquisição de Alimentos e do Programa Nacional de Alimentação Escolar (PNAE). Esses programas representam um importante espaço para o desenvolvimento para os agricultores familiares e suas organizações, as quais podem se traduzir em atividades de baixo carbono.

De acordo com Maluf (2004, p.300), "os empreendimentos agroalimentares de pequeno e médio portes constituem componente central para uma estratégia de desenvolvimento assentada em atividades econômicas promotoras de equidade e de inclusão social, em bases sustentáveis". Assim, a agricultura familiar assume papel central na estratégia para a garantia da segurança alimentar. E, como forma de melhorar a sua eficiência, a adoção de tecnologias de produção para o aumento da competitividade é essencial (Embrapa, 2018).

O olhar para a relação entre energias renováveis e agricultura familiar agora se volta para a internalização das tecnologias de geração de energias alternativas, tais como as de fontes eólica e solar; essa relação é retratada nos trabalhos de Paranhos et al. (2017) e Campos \& De Alcantara (2018). A ideia é que se utilize dessas fontes de energia renováveis para a redução de custos na produção de alimentos principalmente, de modo a proporcionar o acesso a equipamentos e sistemas de produção que melhorem a qualidade dos produtos e proporcionem o aumento da produtividade da agricultura familiar e suas organizações coletivas, no sentido da dinamização dos territórios rurais, ver Nunes et al. (2015).

Atualmente, a principal linha de financiamento para implantar sistemas de geração de energia solar em propriedades de agricultores familiares é o PRONAF Eco. De acordo com o Banco Nacional de Desenvolvimento Econômico e Social (2018), o PRONAF Eco é destinado a agricultores familiares (pessoas físicas) para investimento na utilização de tecnologias de energia renovável, tecnologias ambientais, armazenamento hídrico, pequenos aproveitamentos hidroenergéticos, silvicultura e adoção de práticas conservacionistas e de correção da acidez e fertilidade do solo, visando à recuperação da sua capacidade produtiva.

Outra perspectiva associada à relação entre agricultura familiar e energias renováveis pode ser observada na produção em larga escala de energia de fontes alternativas, principalmente a eólica. Movimento este que veio se intensificando na última década. Neste sentido, a principal política para a promoção do aumento da participação de outras fontes de energias renováveis na matriz energética nacional foi o Programa de Incentivo às Fontes Alternativas de Energia Elétrica (PROINFA), criado em 26 de abril de 2002, pela Lei no 10.438, o qual posteriormente 
foi revisado pela Lei $n^{\circ} 10.762$, de 11 de novembro de 2003, que assegurou a participação de um maior número de estados no programa, o incentivo à indústria nacional e a exclusão dos consumidores de baixa renda do rateio da compra da nova energia (Brasil, 2002).

O PROINFA passou a funcionar em 2004, com o objetivo principal de aumentar as fontes alternativas no Sistema Interligado Nacional (SIN). O intuito foi promover a diversificação da Matriz Energética Brasileira, buscando alternativas para aumentar a segurança no abastecimento de energia elétrica, além de permitir a valorização das características e potencialidades regionais e locais (Agência Nacional de Energia Elétrica, 2015). O programa contou com o suporte do Banco Nacional de Desenvolvimento Social (BNDES), para financiar projetos de geração de energia eólica, Pequenas Centrais Hidrelétricas (PCHs) e biomassa (Bermann, 2008).

De acordo com a Eletrobrás (2018), visto como o maior programa do mundo de incentivo às fontes alternativas de energia elétrica, o PROINFA contribuiu para a diversificação da matriz energética nacional, além de ter fomentado a geração de milhares de empregos diretos e indiretos em todo o país, proporcionando grande avanço industrial e internalização de tecnologia de ponta. Além disso, o programa possibilita a redução de emissões de gases de efeito estufa.

Outra medida que contribuiu para o aumento da participação das energias renováveis na matriz elétrica nacional foi a implementação da Lei no 10.848 , de 15 de março de 2004, que dispõe sobre a comercialização de energia elétrica, define que esta comercialização deve ser realizada nos ambientes de contratação regulada (ACR) e de contratação livre (ACL). Com a implantação da sistemática de leilões como forma principal de contratação da expansão do sistema de geração de eletricidade nacional, a expansão das energias renováveis se consolidou (Losekann \& Hallack, 2018).

Observa-se que, no Brasil, o Estado tem um papel central no incentivo à promoção das fontes de energias renováveis, exercendo a sua influência por meio de atos mandatórios, nos quais a lei torna obrigatória a adição de percentuais de biocombustíveis aos derivados do petróleo e fornece subsídios para a geração de energia eólica, como a redução de tributos e outras medidas (Santos, 2014). A partir desses incentivos e políticas públicas implementadas, o setor eólico nacional apresentou crescimento exponencial, sobretudo na região nordeste do país, que atualmente detém $86 \%$ da capacidade instalada total de energia eólica do Brasil que é cerca de 15 GW (Agência Nacional de Energia Elétrica, 2019).

A produção de energia eólica nacional, ocorre principalmente no litoral e nas regiões rurais do país, dado que esses ambientes têm demonstrado condições mais favoráveis para a garantia do bom aproveitamento energético, como uma produção em larga escala que sobrepõe os custos associados. Assim, o ambiente da agricultura familiar tem sido utilizado para a instalação desses complexos energéticos, o que pode gerar benefícios indiretos para o setor. Rodrigues et al. (2016, p. 18) sugerem que "os municípios que possuem usinas em operação ou construção contêm $48 \%$ mais empresas no setor de agropecuária, o que sugere que a presença de usinas eólicas pode deslocar recursos para o setor agropecuário, dinamizando essa atividade na economia local".

\section{Metodologia}

\section{1 Área de Estudo}

A área da pesquisa compreende os territórios Açu-Mossoró, Mato Grande e Sertão Central Cabugi e Litoral Norte, que estão localizados no Estado do Rio Grande do Norte, conforme destacado no mapa da figura 2. 


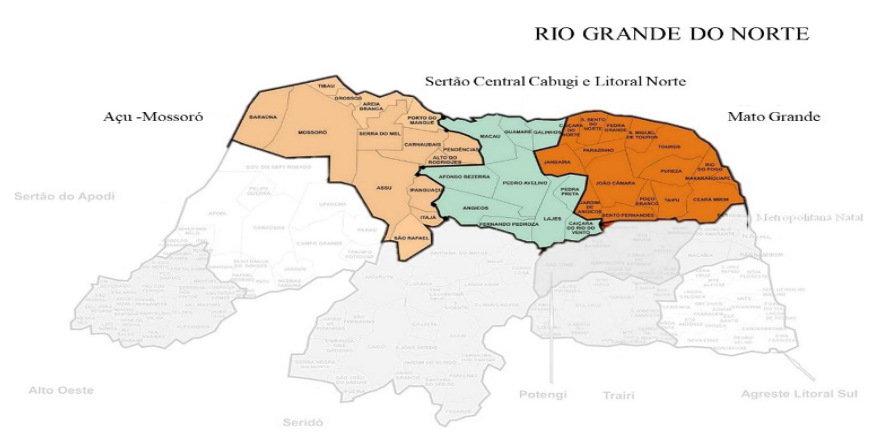

Figura 2 - Área de estudo: territórios rurais do RN.

Fonte: Plano Territorial de Desenvolvimento Rural Sustentável (Sistema de Informações Territoriais, 2010).

Esses territórios foram escolhidos devido à quantidade de parques eólicos instalados nessas regiões, conforme pode ser verificado na figura 3.

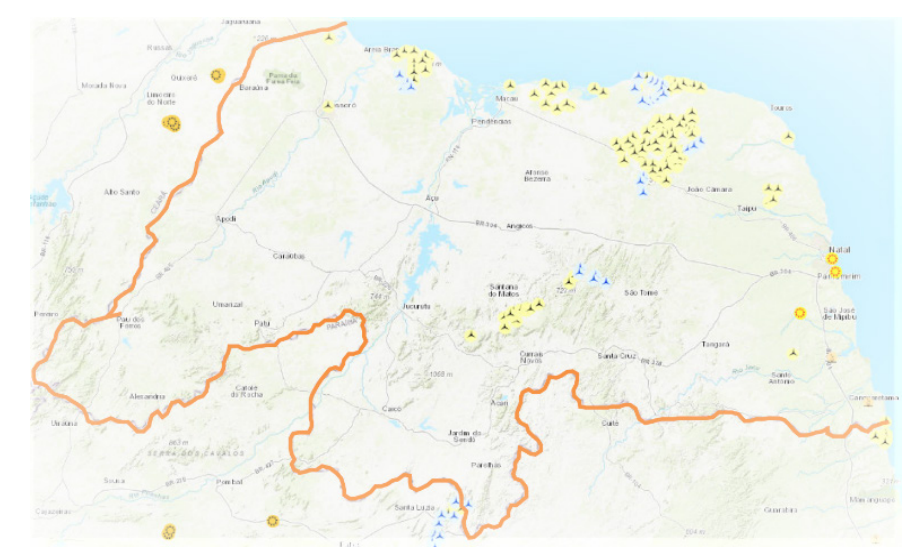

Figura 3 - Distribuição das usinas de geração de eletricidade no RN. Fonte: Web Map (EPE, 2019).

A quantidade de cooperativas da agricultura familiar localizadas em cada um dos territórios também foi levada em consideração para o recorte territorial. A Tabela 1 apresenta tanto a quantidade de cooperativas quanto de parques instalados em cada um dos territórios.

Tabela 1 - Quantidade de usinas eólicas em operação, capacidade instalada em kW e quantidade de cooperativas da agricultura familiar por território.

\begin{tabular}{cccc} 
Território & $\begin{array}{c}\text { Qtd de parques } \\
\text { Eólicos em operação }\end{array}$ & $\begin{array}{c}\text { Capacidade Eólica } \\
(\mathbf{k W})\end{array}$ & $\begin{array}{c}\text { Qtd de } \\
\text { Cooperativas }\end{array}$ \\
$\begin{array}{c}\text { Açu-Mossoró } \\
\text { Agreste Litoral Sul }\end{array}$ & 15 & $379.700,00$ & 10 \\
Mato Grande & 1 & 6,00 & 0 \\
Seridó & 107 & $2.762 .560,00$ & 4 \\
Nerte & 17 & $438.000,00$ & 5 \\
Total & 12 & $473.290,00$ & 8 \\
Nerto Central Cabugi e Litoral & $\mathbf{1 5 2}$ & $\mathbf{4 . 0 5 3 . 5 5 6 , 0 0}$ & $\mathbf{2 7}$ \\
\hline
\end{tabular}

Fonte: Elaborado pelos autores com base nas informações do BIG 21/04/2019 (Agência Nacional de Energia Elétrica, 2019) e no Banco de Dados NEDET-UERN, 2015. 
Assim, como destacado, a área de estudo inclui os territórios Açu-Mossoró, Mato Grande e Sertão Central Cabugi e Litoral Norte. Fazem parte da pesquisa os municípios que possuem cooperativas de agricultores familiares e/ou usinas de geração de energia eólica instalada, conforme apresentado no quadro 1.

Quadro 1 - Municípios que fazem parte do recorte territorial.

\begin{tabular}{|c|c|}
\hline Território & Município \\
\hline Açu-Mossoró & $\begin{array}{l}\text { Assú; Alto do Rodrigues; Areia Branca; Carnaubais; Mossoró; Tibau; } \\
\text { Serra do Mel. }\end{array}$ \\
\hline Mato Grande & $\begin{array}{l}\text { Bento Fernandes; Caiçara do Norte; Ceará-Mirim; Jandaíra; Jardim de } \\
\text { Angicos; João Câmara; Parazinho; Pedra Grande; Pureza; Rio do Fogo; } \\
\text { São Bento do Norte; São Miguel do Gostoso; Touros. }\end{array}$ \\
\hline $\begin{array}{l}\text { Sertão Central Cabugi e } \\
\text { Litoral Norte }\end{array}$ & $\begin{array}{l}\text { Afonso Bezerra; Angicos; Galinhos; Guamaré; Lajes; Macau; Pedra Preta; } \\
\text { Pedro Avelino. }\end{array}$ \\
\hline
\end{tabular}

Fonte: Elaborado pelos autores.

\subsection{Coleta de dados e amostra}

Para fundamentar a realização da pesquisa, as técnicas utilizadas para coleta de dados foram a pesquisa bibliográfica, documental e a pesquisa de campo. Neste sentido, as principais fontes de pesquisa documental utilizadas foram: o Instituto Brasileiro de Geografia e Estatística (IBGE), relatórios divulgados pelo Ministério da Agricultura, Pecuária e Abastecimento (MAPA), Secretaria de Agricultura Familiar e Cooperativismo (SEAD), dados de geração de eletricidade da Agência Nacional de Energia Elétrica (ANEEL), balanços de energia da Empresa de Pesquisa Energética (EPE), Operador Nacional do Sistema (ONS), Anuários Estatísticos, dentre outras.

A partir da definição dos territórios e municípios, foram selecionadas cooperativas de agricultores familiares que participaram das entrevistas, tendo pelo menos uma representante de cada território. A figura 4 apresenta a estratificação da amostra e os critérios utilizados, indicando os municípios e as cooperativas da agricultura familiar que foram entrevistadas em cada um dos respectivos territórios rurais.

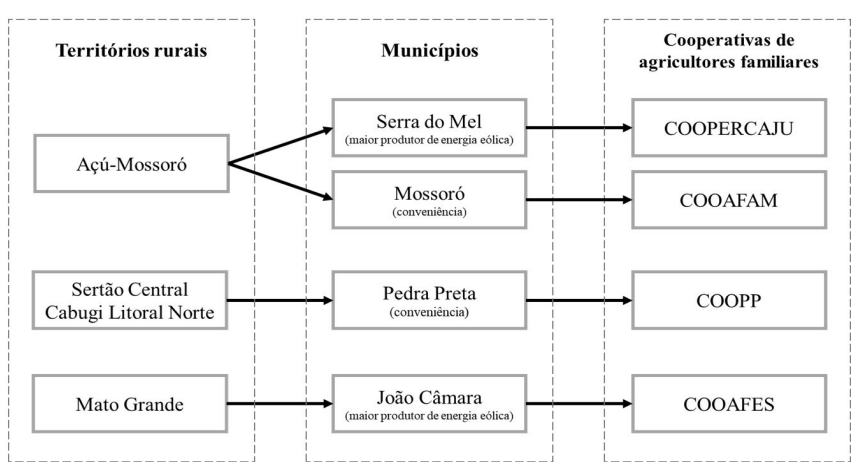

Figura 4 - Estratificação da amostra não probabilística. Fonte: Elaborada pelos autores, 2019.

A Cooperativa dos Beneficiadores Artesanais de Castanha de Caju do Rio Grande do Norte (COOPERCAJU) e a Cooperativa de Agricultores Familiares e Pescadores Artesanais da região do Mato Grande (COAFES) foram selecionadas com base nos critérios estabelecidos incialmente. 
Já a Cooperativa dos Ovinocaprinocultores de Pedra Preta (COOPP) entrou na análise por conveniência, dada a sua disponibilidade para participar da entrevista como representante do território do Sertão Central Cabugi e Litoral Norte. Outra cooperativa selecionada por conveniência para a entrevista foi a Cooperativa de Agricultores e Agricultoras Familiares de Mossoró e Região (COOAFAM), dada a disponibilidade e experiência com projetos de energia solar para irrigação.

\section{Resultados e discussão}

A fim de atender aos critérios da metodologia do Nexus, os resultados são apresentados em três subtópicos, cada um relacionado ao eixo específico de análise, ou seja, agricultura familiar, energias renováveis e construção de mercados com recorte espacial para os territórios Açu-Mossoró, Mato Grande e Sertão Central Cabugi e Litoral Norte.

\subsection{Agricultura familiar e a produção de alimentos nos territórios rurais do RN}

O censo agropecuário de 2017 expôs dados definitivos deste setor de atividade, incluindo dados desagregados para estados e municípios. Assim, os dados específicos para a agricultura familiar (AF) divulgados pelo IBGE foram incluídos na pesquisa a partir do referido censo. Deste modo, algumas análises comparativas entre agricultura familiar e não familiar são apresentadas para sustentar a importância da AF no contexto analisado.

A figura 5 apresenta as proporções da agricultura familiar e não familiar referentes ao número de estabelecimentos, área agrícola e pessoal ocupado por território rural.

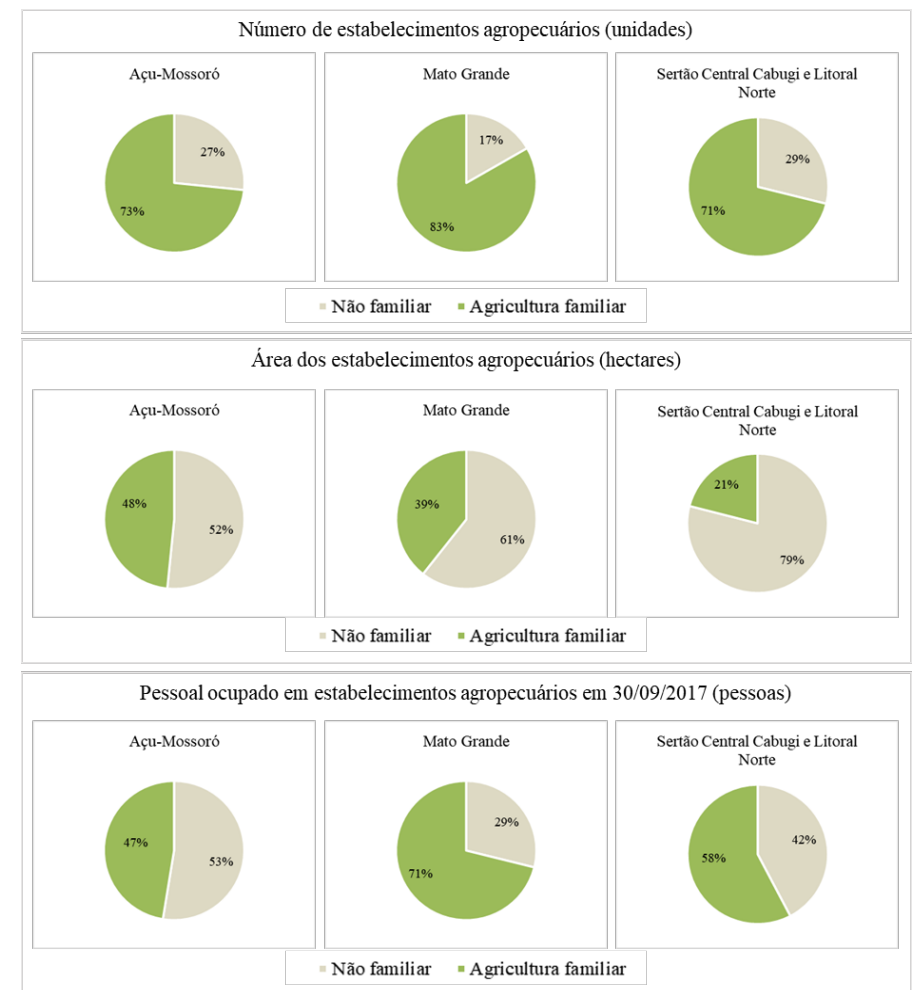

Figura 5 - Proporção agricultura familiar e não familiar por território rural.

Fonte: Elaborada pelos autores a partir do IBGE/SIDRA (Instituto Brasileiro de Geografia e Estatística, 2017). 
A figura 5 mostra que a proporção de estabelecimentos familiares nos territórios está acima de $70 \%$, chegando a $83 \%$ no Mato Grande. E, apesar disso, a área agrícola pertencente à classe de agricultores familiares é menor que $50 \%$ em todos eles, sendo que no território Açu-Mossoró corresponde a 48\%, no Mato Grande a 39\% e no Sertão Central Cabugi e Litoral Norte a apenas $21 \%$. Constatando-se que a maior parte das terras pertence ao setor agropecuário não familiar. Destacando que o território Sertão Central Cabugi e Litoral Norte é o que apresenta maior concentração de terras da agricultura não familiar (79\%). No território Açu-Mossoró, verificase que $47 \%$ do pessoal ocupado no setor agropecuário advém da agricultura familiar e, nos territórios Mato Grande e Sertão Central Cabugi e Litoral Norte, esses percentuais chegam a $71 \%$ e $58 \%$, respectivamente.

A produção agropecuária no Rio Grande do Norte apresenta grandes desafios, principalmente relacionados às características climáticas da região. De acordo com o Instituto Brasileiro de Geografia e Estatística (2017), o território do Rio Grande do Norte pertence quase totalmente ao semiárido brasileiro. Cerca de $90 \%$ dos municípios (147 dos 167) são classificados com clima semiárido, sendo que um dos indicadores utilizados para essa denominação é o percentual diário de déficit hídrico igual ou superior a $60 \%$, ou seja, os totais pluviométricos são baixos e apresentam alta variabilidade no tempo e no espaço, a distribuição das chuvas é marcadamente sazonal. Como reflexo das condições climáticas dominantes de semiaridez, a hidrografia é pobre, em seus amplos aspectos. As condições hídricas são insuficientes para sustentar rios caudalosos que se mantenham perenes nos longos períodos de ausência de precipitações (Instituto Brasileiro de Geografia e Estatística, 2017; Zanella, 2014).

Lançando-se o olhar para a agricultura familiar no Estado do Rio Grande do Norte, esses fatores tornam-se ainda mais complexos, dado que, além das condições naturais requeridas para a produção, os pequenos agricultores, em geral, não têm se beneficiado de melhorias em tecnologias e práticas agrícolas, nem estão organizados coletivamente para melhorar sua produtividade ou sua posição no mercado. A agricultura familiar tem a importância essencial para o Estado, se não do ponto de vista de receita e PIB, mas sob a lógica da geração de emprego e renda para os trabalhadores do campo (Secretaria de Estado do Planejamento e das Finanças, 2013).

Em termos econômicos, o Valor Adicionado Bruto (VAB) da agropecuária no Estado do Rio Grande do Norte tem apresentado forte crescimento em todos os territórios no período analisado (2002-2016), conforme mostra o gráfico da figura 6.

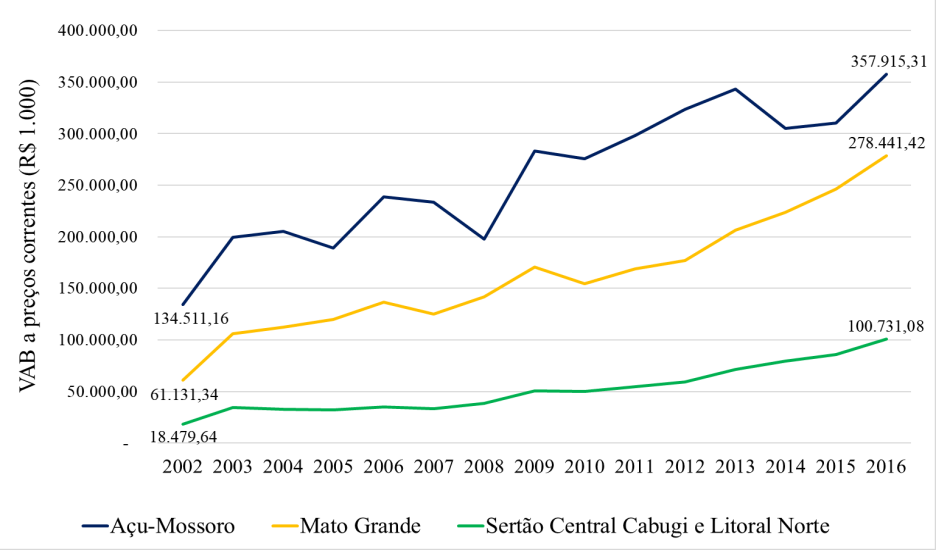

Figura 6 - Valor adicionado bruto da Agropecuária nos territórios (2002-2016). Fonte: Elaborada pelos autores a partir do IBGE/SIDRA (Instituto Brasileiro de Geografia e Estatística, 2017). 
Apesar da tendência de crescimento observada no período avaliado, a representatividade do setor agropecuário no PIB dos territórios rurais é muito pequena. Sendo 3,9\% no território Açu-Mossoró, 3,4\% no Sertão Central Cabugi e Litoral Norte e 7\% no Mato Grande, para o ano de 2016.

Utilizando os dados do censo agropecuário de 2017, diretamente relacionados à agricultura familiar, verifica-se que a maior parte da receita obtida pelo setor agropecuário no Estado do Rio Grande do Norte advém da agricultura não familiar, cerca de $63 \%$ da receita total. Nos territórios rurais analisados, as proporções da receita gerada pela agricultura familiar variam conforme apresentado nos gráficos da figura 7.

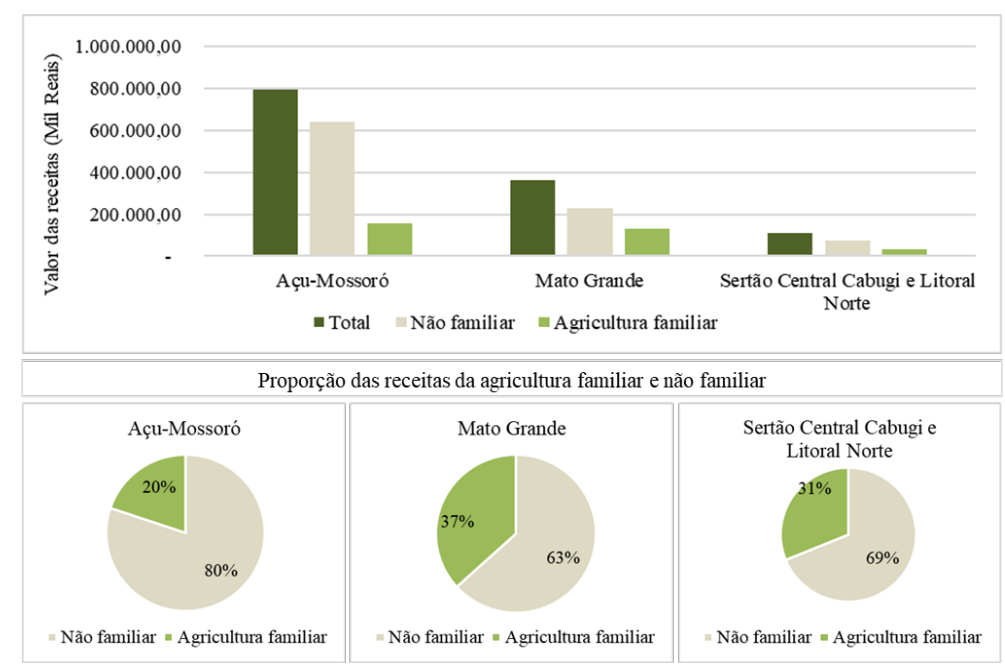

Figura 7 - Receita proveniente da agricultura familiar e não familiar nos territórios rurais. Fonte: Elaborada pelos autores a partir de IBGE/SIDRA (Instituto Brasileiro de Geografia e Estatística, 2017).

Verifica-se que há um grande contraste que permeia o setor agrícola familiar, pois detém a maior parte dos estabelecimentos e de mão de obra empregada no setor agropecuário do Estado e dos territórios rurais, todavia tem menor participação na receita total em todos os casos. Sendo que o território do Açu-Mossoró é o que apresenta a maior concentração de renda da atividade agrícola não familiar, cerca de $80 \%$ do total. A Tabela 2 mostra a relação dos municípios que apresentaram uma maior participação da agricultura familiar nas receitas agropecuárias registradas no censo de 2017.

Tabela 2 - Municípios onde as receitas obtidas pelos estabelecimentos da agricultura familiar superam a não familiar por território de acordo com o censo agropecuário de 2017. Continua

\begin{tabular}{|c|c|c|c|c|c|c|}
\hline Território rural & Município & $\begin{array}{l}\text { Total } \\
\text { (Mil } \\
\text { reais) }\end{array}$ & $\begin{array}{c}\text { Não } \\
\text { familiar } \\
\text { (Mil } \\
\text { reais) }\end{array}$ & $\%$ & $\begin{array}{l}\text { Agricultura } \\
\text { familiar } \\
\text { (Mil reais) }\end{array}$ & $\%$ \\
\hline \multirow[t]{7}{*}{ Açu-Mossoró } & Grossos & $2.046,00$ & 300,00 & $15 \%$ & 1746 & $85 \%$ \\
\hline & Porto do Mangue & $3.153,00$ & 506,00 & $16 \%$ & 2647 & $84 \%$ \\
\hline & Serra do Mel & $32.931,00$ & $7.585,00$ & $23 \%$ & 25345 & $77 \%$ \\
\hline & Areia Branca & $5.187,00$ & $1.557,00$ & $30 \%$ & 3630 & $70 \%$ \\
\hline & São Rafael & $12.422,00$ & $4.023,00$ & $32 \%$ & 8400 & $68 \%$ \\
\hline & Carnaubais & $19.457,00$ & $8.022,00$ & $41 \%$ & 11435 & $59 \%$ \\
\hline & Itajá & $5.302,00$ & $2.198,00$ & $41 \%$ & 3104 & $59 \%$ \\
\hline
\end{tabular}

Fonte: Elaborada pelos autores a partir do IBGE/SIDRA (Instituto Brasileiro de Geografia e Estatística, 2017). 
Tabela 2 - Continuação...

\begin{tabular}{llccccc}
\hline Território rural & \multicolumn{1}{c}{ Município } & $\begin{array}{c}\text { Total } \\
\text { (Mil } \\
\text { Meais) }\end{array}$ & $\begin{array}{c}\text { Não } \\
\text { familiar } \\
\text { (Mil } \\
\text { reais) }\end{array}$ & $\begin{array}{c}\text { Agricultura } \\
\text { familiar } \\
\text { (Mil reais) }\end{array}$ & $\%$ \\
& $\begin{array}{l}\text { São Miguel do } \\
\text { Gostoso }\end{array}$ & $5.177,00$ & 517,00 & $10 \%$ & 4660 & $90 \%$ \\
& Poço Branco & $5.847,00$ & $1.543,00$ & $26 \%$ & 4304 & $74 \%$ \\
& João Câmara & $27.664,00$ & $8.947,00$ & $32 \%$ & 18717 & $68 \%$ \\
& Bento Fernandes & $14.420,00$ & $5.424,00$ & $38 \%$ & 8996 & $62 \%$ \\
& Parazinho & $8.338,00$ & $3.569,00$ & $43 \%$ & 4770 & $57 \%$ \\
Sertão Central & Caiçara do Norte & $2.776,00$ & $1.250,00$ & $45 \%$ & 1527 & $55 \%$ \\
Cabugi e Litoral & Rio do Fogo & $8.237,00$ & $3.808,00$ & $46 \%$ & 4429 & $54 \%$ \\
Norte & Pedra Preta & $4.467,00$ & $1.362,00$ & $30 \%$ & 3105 & $70 \%$ \\
& Caiçara do Rio do & $2.840,00$ & $1.140,00$ & $40 \%$ & 1701 & $60 \%$ \\
& Vento & & & & & \\
& Lajes & $11.042,00$ & $5.391,00$ & $49 \%$ & 5650 & $51 \%$ \\
\hline
\end{tabular}

Fonte: Elaborada pelos autores a partir do IBGE/SIDRA (Instituto Brasileiro de Geografia e Estatística, 2017).

De acordo com os dados apresentados na Tabela 2, em alguns municípios, a participação das receitas geradas pela agricultura familiar está acima de $75 \%$. Como é o caso das cidades de Grossos (85\%), Porto do Mangue (84\%) e Serra do Mel (77\%), todas no território Açu-Mossoró, e a cidade de São Miguel do Gostoso (90\%), no território Mato Grande. A cidade com maior representatividade do setor agrícola familiar no território do Sertão Central Cabugi e Litoral Norte é Pedra Preta, com uma participação de $70 \%$ na receita total agropecuária do município.

De modo geral, conforme apontado pelo Relatório de identificação e mapeamento das aglomerações produtivas do Estado do Rio Grande do Norte, realizado pela Seplan, dentro do projeto RN Sustentável, as principais cadeias produtivas da agropecuária no Rio Grande do Norte são a agricultura irrigada, leite e derivados, avicultura, cajucultura, mandiocultura, cocoicultura, apicultura, ovinocaprinocultura, a piscicultura e pesca artesanal e o cultivo de feijão (Secretaria de Estado do Planejamento e das Finanças, 2016). Ainda de acordo com este relatório, os territórios Açu-Mossoró, Mato Grande e Sertão Central Cabugi e Litoral Norte, apresentam arranjos produtivos locais com algumas cadeias predominantes, as quais são relacionadas no quadro 2 .

Quadro 2 - Arranjos produtivos locais (APLs) por território.

\begin{tabular}{|c|c|}
\hline Territórios & Arranjos Produtivos Locais (APLs) \\
\hline Açu-Mossoró & $\begin{array}{l}\text { Agricultura Irrigada, Cajucultura, Leite e derivados, } \\
\text { ovinocaprinocultura, piscicultura e pesca. }\end{array}$ \\
\hline Mato Grande & $\begin{array}{l}\text { Agricultura Irrigada, Cajucultura, Leite e derivados, } \\
\text { piscicultura e pesca. }\end{array}$ \\
\hline Sertão Central Cabugi e Litoral Norte & Ovinocaprinocultura, piscicultura. \\
\hline
\end{tabular}

Fonte: Secretaria de Estado do Planejamento e das Finanças (2016).

Os APLs presentes nos territórios mostram que o Açu-Mossoró e Mato Grande apresentam perfis muito próximos, no que se refere ao potencial para a produção agroalimentar. Nestes territórios, há uma grande possibilidade de diversificação para a agricultura familiar, 
diferente do território Sertão Central Cabugi e Litoral Norte que tem como foco principal a ovinocaprinocultura e psicultura.

Durante a pesquisa de campo realizada, foi possível observar que as cooperativas entrevistadas em cada um dos territórios se encontram inseridas em pelo menos um desses arranjos produtivos presentes nestas localidades.

O quadro 3 apresenta alguns excertos das entrevistas realizadas com os gestores das cooperativas com perguntas específicas para o eixo da produção de alimentos pela agricultura familiar que contribuem para melhor compreensão dessa dinâmica em cada território.

Quadro 3 - Eixo de Agricultura familiar: Produção de alimentos.

\begin{tabular}{|c|c|}
\hline Territórios & Excertos das entrevistas \\
\hline Açu-Mossoró & $\begin{array}{l}\text { COOAFAM (Mossoró): "a polpa de fruta, a galinha caipira, a fruta, o melão, } \\
\text { mamão, a melancia, frutas de saladas pra merenda das escolas e hortaliças". } \\
\text { COOPERCAJU (Serra do Mel): "só amêndoa de castanha". }\end{array}$ \\
\hline Mato Grande & COOAFES (João Câmara): "fruticultura e apicultura." \\
\hline $\begin{array}{l}\text { Sertão Central } \\
\text { Cabugi e Litoral } \\
\text { Norte }\end{array}$ & $\begin{array}{l}\text { COOPP (Pedra Preta): "A gente comercializou há uns quatro anos atrás o } \\
\text { produto de bovinocultura, a carne, mas aí nós tivemos alguns problemas com } \\
\text { relação à legislação pra poder abater e tivemos que paralisar, aí agora a gente tá } \\
\text { tentando retomar com a produção de leite, no caso o beneficiamento." }\end{array}$ \\
\hline
\end{tabular}

Fonte: Pesquisa de campo.

Como observado no quadro 3, os territórios Açu-Mossoró e Mato Grande são os que demonstram maiores potencialidades para diversificação, isso também foi confirmado através das entrevistas. Já as cadeias exploradas dentro do território Sertão Central Cabugi e Litoral Norte são restritas e, mesmo reconhecendo tamanha diversidade da agricultura familiar (aspecto observado na fala do presidente da cooperativa), enfatiza-se o foco na produção de alimentos oriundos dos principais APLs presentes nesta região, ou seja, aqueles de origem da ovinocaprinocultura.

\subsection{Caracterização das Energias Renováveis nos Territórios Açu-Mossoró, Mato Grande e Sertão Central Cabugi e Litoral Norte}

Como mencionado, o território do Rio Grande do Norte encontra-se quase totalmente inserido no semiárido nordestino. Todavia, alguns fatores são benéficos neste tipo de clima, principalmente no que se refere às condições necessárias para a produção de energia proveniente de fontes eólica e solar. Assim, a predominância do clima semiárido na região coloca o RN em condição privilegiada, dadas as boas características naturais abundantes para a geração de energia elétrica a partir das fontes renováveis supracitadas. Atualmente o Estado é responsável por $26,9 \%$ da geração de energia eólica nacional e quase 1/3 (31,3\%) da produção no Nordeste.

Em 2003, a Companhia Energética do Rio Grande do Norte (COSERN) publicou o Atlas Eólico, um documento estratégico para o Estado, que apresenta análises e projeções, compondo o diagnóstico sobre as possibilidades de inserção da fonte eólica na matriz energética estadual e suas potenciais externalidades como benefício à população do Estado do Rio Grande do Norte (Companhia Energética do Rio Grande do Norte, 2003). Ressalta-se ainda, neste estudo, a identificação das áreas mais promissoras, trazendo informações que nortearam a posterior instalação dos parques eólicos no Estado. De acordo com o Atlas Eólico, em todas as regiões, foram constatados ventos com velocidades médias anuais entre 8,0 e $8,5 \mathrm{~m} / \mathrm{s}$ (a $50 \mathrm{~m}$ de altura) 
nas melhores áreas (Companhia Energética do Rio Grande do Norte, 2003). A Figura 8 mostra o mapeamento do potencial eólico do RN atualizado pelo Global Wind Atlas.

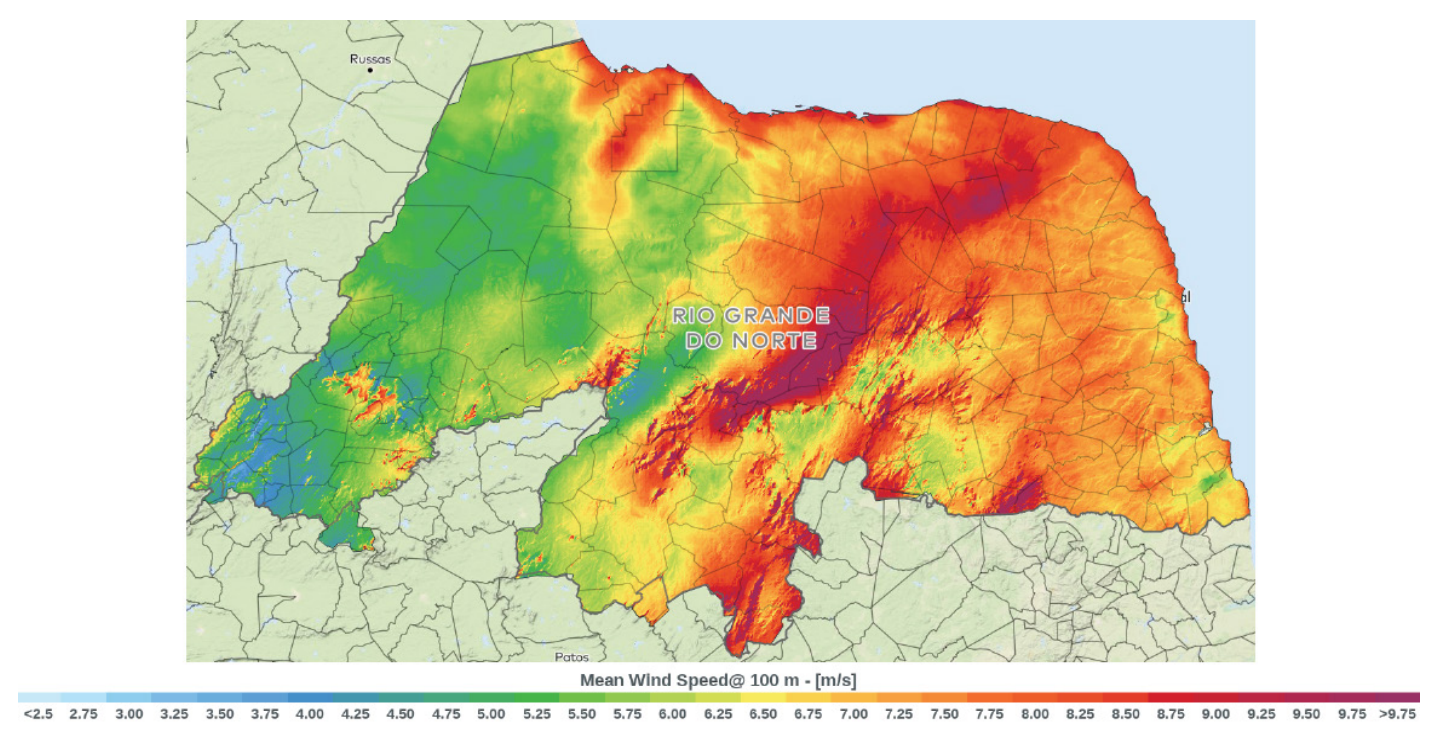

Figura 8 - Potencial Eólico do RN: áreas mais promissoras para os empreendimentos.

Fonte: https://globalwindatlas.info/ em 10/12/2019 (2019).

Segundo dados publicados pelo Banco de Informações de Geração de responsabilidade da ANEEL, a capacidade instalada para geração de energia eólica no Estado do Rio Grande do Norte era de 4.057 .756 kW de potência, proveniente de 152 parques em operação na região, conforme a Tabela 3. Sendo que está prevista a adição de $2.259 .210 \mathrm{~kW}$ de potência, com a implementação de 3 usinas que estão em construção e 57 com construção ainda não iniciada (outorgadas).

Tabela 3 - Usinas eólicas em operação, em construção e outorgadas por município.

\begin{tabular}{|c|c|c|c|c|c|c|c|c|c|}
\hline \multirow[b]{2}{*}{ Território } & \multirow[b]{2}{*}{ Município } & \multicolumn{2}{|c|}{ Em operação } & \multicolumn{2}{|c|}{ Em construção } & \multicolumn{2}{|c|}{ Outorgadas } & \multicolumn{2}{|c|}{ Total } \\
\hline & & Usinas & $\begin{array}{c}\text { Potência } \\
\text { (kW) } \\
\text { outorgada }\end{array}$ & Usinas & $\begin{array}{c}\text { Potência } \\
\text { (kW) } \\
\text { outorgada }\end{array}$ & Usinas & $\begin{array}{c}\text { Potência } \\
\text { (kW) } \\
\text { outorgada }\end{array}$ & Usinas & $\begin{array}{c}\text { Potência } \\
\text { (kW) } \\
\text { outorgada }\end{array}$ \\
\hline \multirow[t]{2}{*}{ Açu-Mossoró } & Serra do Mel & 9 & 219.300 & 1 & 31.185 & 14 & 461.425 & 24 & 711.910 \\
\hline & Areia Branca & 6 & 160.400 & 0 & - & 0 & - & 6 & 160.400 \\
\hline \multirow[t]{12}{*}{ Mato Grande } & João Câmara & 29 & 742.360 & 0 & - & 0 & - & 29 & 742.360 \\
\hline & Parazinho & 22 & 629.200 & 0 & - & 0 & - & 22 & 629.200 \\
\hline & São Bento do Norte & 15 & 361.400 & 0 & - & 2 & 141.900 & 17 & 503.300 \\
\hline & Pedra Grande & 12 & 220.600 & 0 & - & 1 & 42.000 & 13 & 262.600 \\
\hline & Jandaíra & 7 & 218.700 & 0 & - & 0 & - & 7 & 218.700 \\
\hline & $\begin{array}{l}\text { São Miguel do } \\
\text { Gostoso }\end{array}$ & 9 & 216.200 & 2 & 60.300 & 4 & 163.800 & 15 & 440.300 \\
\hline & Ceará-Mirim & 5 & 145.800 & 0 & - & 0 & - & 5 & 145.800 \\
\hline & Touros & 4 & 98.400 & 0 & - & 8 & 174.300 & 12 & 272.700 \\
\hline & Rio do Fogo & 2 & 77.300 & 0 & - & 3 & 71.300 & 5 & 148.600 \\
\hline & Jardim de Angicos & 2 & 56.800 & 0 & - & 0 & - & 2 & 56.800 \\
\hline & Bento Fernandes & 0 & - & 0 & - & 7 & 441.000 & 7 & 441.000 \\
\hline & Caiçara do Norte & 0 & - & 0 & - & 2 & 71.400 & 2 & 71.400 \\
\hline
\end{tabular}

Fonte: Elaborada pelos autores a partir do BIG 04/08/2019, Agência Nacional de Energia Elétrica (2019). 
Tabela 3 - Continuação...

\begin{tabular}{|c|c|c|c|c|c|c|c|c|c|}
\hline \multirow[b]{2}{*}{ Território } & \multirow[b]{2}{*}{ Município } & \multicolumn{2}{|c|}{ Em operação } & \multicolumn{2}{|c|}{ Em construção } & \multicolumn{2}{|c|}{ Outorgadas } & \multicolumn{2}{|c|}{ Total } \\
\hline & & Usinas & $\begin{array}{c}\text { Potência } \\
\text { (kW) } \\
\text { outorgada }\end{array}$ & Usinas & $\begin{array}{c}\text { Potência } \\
\text { (kW) } \\
\text { outorgada }\end{array}$ & Usinas & $\begin{array}{c}\text { Potência } \\
\text { (kW) } \\
\text { outorgada }\end{array}$ & Usinas & $\begin{array}{c}\text { Potência } \\
\text { (kW) } \\
\text { outorgada }\end{array}$ \\
\hline Sertão & Guamaré & 8 & 284.450 & 0 & - & 0 & - & 8 & 284.450 \\
\hline Central & Galinhos & 2 & 118.570 & 0 & - & 0 & - & 2 & 118.570 \\
\hline Cabugi e & Macau & 2 & 70.270 & 0 & - & 0 & - & 2 & 70.270 \\
\hline Litoral Norte & Lajes & 0 & - & 0 & - & 8 & 285.600 & 8 & 285.600 \\
\hline & Pedra Preta & 0 & - & 0 & - & 1 & 29.400 & 1 & 29.400 \\
\hline & Pedro Avelino & 0 & - & 0 & - & 3 & 168.000 & 3 & 168.000 \\
\hline Total & & 134 & 3.619 .750 & 3 & 91.485 & 53 & 2.050 .125 & 190 & 5.761 .360 \\
\hline
\end{tabular}

Fonte: Elaborada pelos autores a partir do BIG 04/08/2019, Agência Nacional de Energia Elétrica (2019).

A maior concentração das usinas de geração de energia eólica está no território do Mato Grande, o qual detém uma capacidade instalada de 2.766 .760 kW de potência, com um total de 107 empreendimentos em operação, distribuídos em 10 municípios, o que representa atualmente $68 \%$ do total produzido no Estado. Ainda está prevista a adição de $1.166 .000 \mathrm{~kW}$ de potência de acordo com os projetos em construção e outorgados. Deste modo, na região do Mato Grande, serão adicionados mais 29 parques eólicos, sendo que 2 encontram-se em fase de implantação na cidade de São Miguel do Gostoso.

No território Açu-Mossoró, há apenas duas cidades que sediaram a implantação de parques eólicos, até o momento, conforme mostra a Tabela 3, são elas Serra do Mel e Areia Branca, com 9 e 6 usinas instaladas, respectivamente. O primeiro parque instalado nesse território foi na cidade de Areia Branca, no início de 2013. A usina Mel II possui capacidade instalada de $20 \mathrm{MW}$, distribuídas em um total de 10 aerogeradores, produzindo energia para todo o território nacional, através do Sistema Interligado Nacional (SIN), pertencente ao grupo Neoenergia.

Observando ainda os dados da Tabela 3, verifica-se que o município de Serra do Mel é o maior produtor de energia eólica no território Açu-Mossoró, sendo que a primeira usina foi instalada no ano de 2015. Fazendo um paralelo dos dados analisados nesse eixo do Nexus com as entrevistas realizadas, verificam-se alguns pontos de concordância e algumas contradições em termos de benefícios percebidos para o setor específico da agricultura familiar nessas localidades de acordo com o Quadro 4.

Quadro 4 - Eixo de Energias Renováveis: Visão dos gestores das cooperativas.

\begin{tabular}{|l|l|}
\hline Territórios & \multicolumn{1}{c|}{ Excertos das entrevistas } \\
\hline \multirow{5}{*}{ Açu-Mossoró } & $\begin{array}{l}\text { COOAFAM (Mossoró): "Até onde eu sei, na Serra do Mel, essas áreas passam } \\
\text { na produção, passam nas áreas dos lotes, então se houve algum impacto foi na } \\
\text { plantação, nos cajueiros, mas não foi algo assim tão... eu acredito que o benefício } \\
\text { na vida do agricultor, do produtor, foi maior do que o que ele perdeu, ou seja, } \\
\text { coisa que ele plantou e vai replantar." } \\
\text { COOPERCAJU (Serra do Mel): "[...] ela vem e se instala dentro da propriedade do } \\
\text { cara, aquela parte onde ela passa ali, as plantas, o que tiver ela arranca tudo né, } \\
\text { vai ficar... a terra vai ficar ocupada com outra coisa." }\end{array}$ \\
\hline Mato Grande & $\begin{array}{l}\text { COOAFES (João Câmara): "[...] temos ciência, temos acompanhado, mudou até a } \\
\text { paisagem da região do Mato Grande, né, com os geradores de energia... agora é } \\
\text { uma energia que é vendida direto pra outra companhia, né? Não é uma energia } \\
\text { que tem programa direcionado aà produção agrícola do pequeno, do agricultor } \\
\text { familiar. Então a gente tem ciência, mas também não temos acesso." }\end{array}$ \\
\hline
\end{tabular}

Fonte: Pesquisa de campo. 
Quadro 4 - Continuação...

\begin{tabular}{l|l}
\multicolumn{1}{c}{ Territórios } & \multicolumn{1}{c}{ Excertos das entrevistas } \\
Sertão Central & COOPP (Pedra Preta): "Agora assim, é uma questão que a gente fica analisando \\
Cabugi e & $\begin{array}{l}\text { os dois lados, deixa recursos, mas são pra poucos moradores. [...] a renda vai ficar } \\
\text { muito concentrada em grandes produtores." }\end{array}$ \\
Litoral Norte & monton
\end{tabular}

Fonte: Pesquisa de campo.

Observa-se, através da fala dos gestores das cooperativas, que também são agricultores familiares, que ainda há muita dúvida a respeito desse novo cenário de inserção das energias renováveis, especialmente os parques eólicos que estão se instalando em suas áreas produtivas. De um lado, a visão é positiva, como é a demonstrada pela COOAFAM ao levantar a hipótese de que a renda gerada pelo arrendamento das terras pode ajudar os agricultores a produzirem mais, investir nas suas terras e torná-las mais eficientes.

Por outro lado, ainda há muita falta de informação, como as questões levantadas pelo presidente da COOPERCAJU. Não está claro se de fato a renda gerada pelo arredamento das terras é justa ou se isso irá gerar prejuízos futuros, porque, como observado por ele, as terras ficam inacessíveis, em muitos casos, e isso pode reduzir a produtividade do agricultor familiar na região. Já o presidente de COOAFES enfatiza a necessidade de intervenção do poder público. Por fim, o presidente da COOPP observa que os grandes produtores da região é que serão os maiores beneficiados com o arredamento das terras, pois nessa região há participação de áreas extensas concentradas em um pequeno número de estabelecimentos.

A Tabela 4 apresenta a quantidade de estabelecimentos da agricultura familiar e não familiar nos territórios Açu-Mossoró, Mato Grande e Sertão Central Cabugi e Litoral Norte, de acordo com o censo agropecuário 2017.

Tabela 4 - Número de estabelecimentos da agricultura familiar e não familiar por território.

\begin{tabular}{lccc}
\multirow{2}{*}{ Territórios Rurais } & \multicolumn{3}{c}{$N^{\circ}$ Estabelecimentos agropecuários (Unidades) } \\
\cline { 2 - 4 } & Total & Não familiar & Agricultura familiar \\
Açu-Mossoró & 6893 & 1836 & 5057 \\
Mato Grande & 6954 & 1160 & 5794 \\
Sertão Central Cabugi e Litoral Norte & 2279 & 658 & 1621 \\
\hline
\end{tabular}

Fonte: Elaborada pelos autores a partir do IBGE/SIDRA (Instituto Brasileiro de Geografia e Estatística, 2017).

Além dos dados referentes ao número de estabelecimentos da agricultura familiar, outro dado importante para esta análise refere-se à quantidade de Declarações de Aptidão ao Programa Nacional de Fortalecimento da Agricultura Familiar (DAP) emitidas no período para pessoa física e jurídica, visto que é o instrumento básico para acesso às políticas públicas orientadas à agricultura familiar. Assim, a Tabela 5 mostra o número de DAPs ativas e inativas por território, bem com as de pessoas jurídicas. Esse conjunto de dados fornece indícios do potencial de aproveitamento dos programas pelos pequenos agricultores.

Tabela 5 - Número de DAPs ativas e inativas por Território.

\begin{tabular}{lccccc}
\multirow{2}{*}{ Territórios Rurais } & \multicolumn{3}{c}{$\mathbf{N}^{\mathbf{0}}$ de DAP Principal } & & $\begin{array}{c}\mathbf{N}^{0} \text { de DAP } \\
\text { Jurídica }\end{array}$ \\
\cline { 2 - 5 } Açu-Mossoró & Ativas & Inativas & Total & $\%$ & \\
Mato Grande & 6.808 & 22.483 & 29.291 & $23,2 \%$ & 20 \\
Sertão Central Cabugi e Litoral Norte & 8.292 & 18.996 & 27.288 & $30,4 \%$ & 30 \\
\hline
\end{tabular}

Fonte: Elaborada pelos autores a partir do smp14, Secretaria Especial de Agricultura Familiar e do Desenvolvimento Agrário (2019). 
Na Tabela 5, verifica-se que o número de DAPs ativas de pessoas físicas é superior à quantidade de estabelecimentos da agricultura familiar registrados pelo censo de 2017 para todos os territórios avaliados, com exceção do Açu-Mossoró. Levando em consideração que só é permitida uma DAP por unidade familiar, chamada de DAP principal, pode-se dizer que todos os agricultores familiares estão habilitados a ter acesso às políticas públicas. Além disso, a quantidade de DAPs inativas revela que o número de agricultores que poderiam estar atuando nos mercados institucionais é ainda mais expressivo. Já a quantidade de DAPs de pessoa jurídica é bastante reduzida, levando-se em consideração o número de agricultores familiares em cada território. Esse tipo de DAP é emitida para cooperativas e/ou associações. Para tanto, é um indicador de que existe dificuldade de organização coletiva dos produtores nessas regiões para a comercialização conjunta dos produtos. Sendo assim, realizou-se o mapeamento das cooperativas presentes em cada um dos territórios. Conforme dados apresentados na Tabela 6.

Tabela 6 - Quantidade de Cooperativas por Território.

\begin{tabular}{|c|c|c|c|}
\hline Território & Qtd Cooperativas & Com DAP ativa & $\%$ \\
\hline Açu-Mossoró & 15 & 6 & $40,0 \%$ \\
\hline Mato Grande & 8 & 2 & $25,0 \%$ \\
\hline Sertão Central Cabugi e Litoral Norte & 8 & 2 & $25,0 \%$ \\
\hline Total & 31 & 10 & $32,3 \%$ \\
\hline
\end{tabular}

Fonte: Elaborada pelos autores a partir do Banco de Dados NEDET-UERN, 2015; smp14, Secretaria Especial de Agricultura Familiar e do Desenvolvimento Agrário (2019).

De acordo com a Tabela 6, o território Açu-Mossoró concentra o maior número de cooperativas, entretanto apenas 40\% possuem DAP ativa. Nos territórios Mato Grande e Sertão Central Cabugi e Litoral Norte, essa participação é ainda menor, somente $25 \%$ das cooperativas identificadas na região detêm DAP ativa. A evolução do PRONAF por cada território pode ser verificada na figura 9.

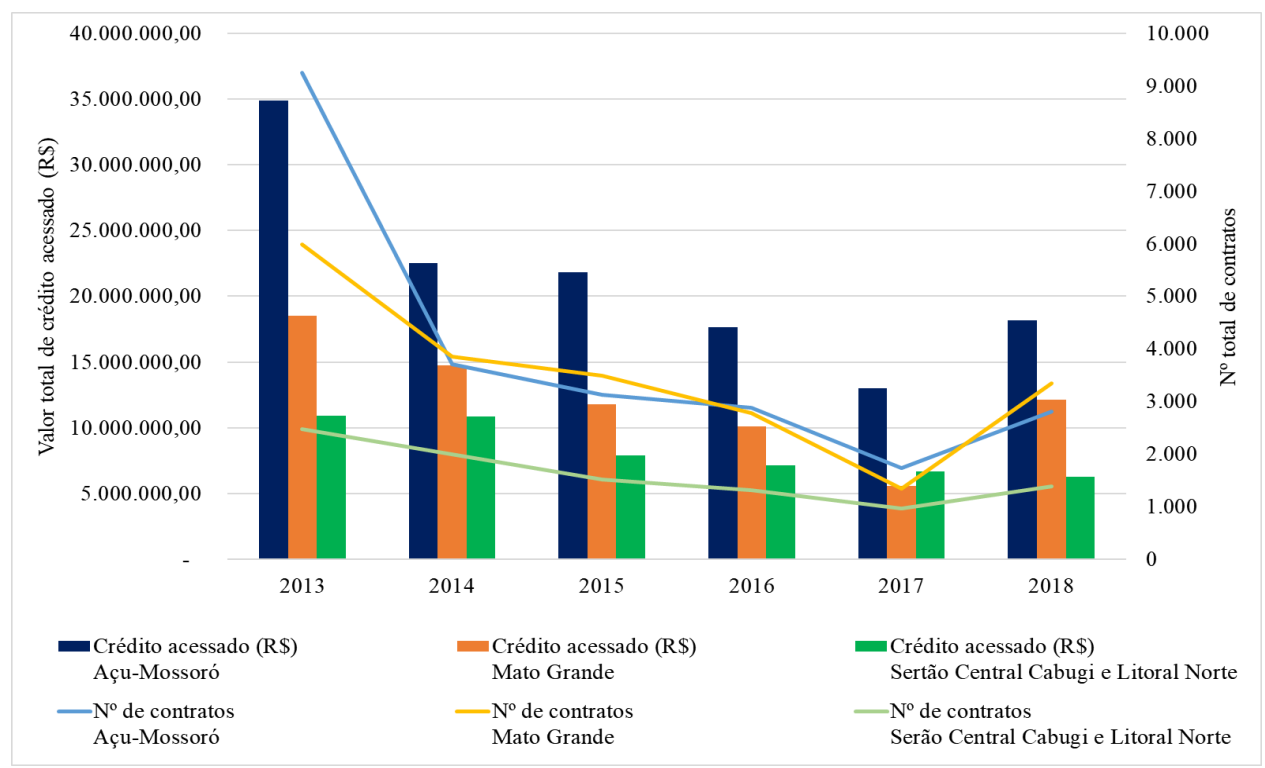

Figura 9 - Evolução dos contratos e crédito do PRONAF por Território (2013 a 2018).

Fonte: Elaborada pelos autores a partir do Painel de Monitoramento de Políticas da Secretaria Especial de Agricultura Familiar e do Desenvolvimento Agrário (2019). 
O gráfico da figura 9 mostra tendência de redução do crédito e do total de contratos para os territórios no período 2013-2017, sendo que, em 2018, o volume tanto monetário quanto de projetos voltou a crescer, com o maior aumento observado para o território do Mato Grande, saindo de um total de 1.339 contratos, em 2017, para 3349, em 2018, um crescimento de $150,1 \%$, sendo que para o crédito o crescimento registrado nesse mesmo período foi de $117 \%$. No território Açu-Mossoró, o aumento foi de $62,1 \%$ no número de projetos e $39,7 \%$ no volume de recursos do PRONAF. Para compreender melhor o cenário em termos de quantidade de atendimentos e de famílias beneficiadas, a Tabela 7 traz dados por território.

Tabela 7 - Evolução do número de atendimento e de famílias beneficiadas com ATER por território (2011 a 2018).

\begin{tabular}{|c|c|c|c|c|c|c|c|c|c|}
\hline Território & ATER & 2011 & 2012 & 2013 & 2014 & 2015 & 2016 & 2017 & 2018 \\
\hline \multirow[t]{2}{*}{ Açu-Mossoró } & $\mathrm{N}^{\circ}$ de atendimentos & 826 & 290 & 1.241 & 1.962 & 2.642 & 3.661 & 2.810 & 748 \\
\hline & $\begin{array}{l}N^{0} \text { de famílias } \\
\text { beneficiadas }\end{array}$ & 159 & 137 & 645 & 581 & 644 & 596 & 526 & 286 \\
\hline \multirow[t]{2}{*}{ Mato Grande } & $\mathrm{N}^{\circ}$ de atendimentos & 4.182 & 1.461 & 5.096 & 10.662 & 10.271 & 2.397 & 1.530 & 0 \\
\hline & $\begin{array}{l}N^{\circ} \text { de famílias } \\
\text { beneficiadas }\end{array}$ & 1.184 & 801 & 1.575 & 2.501 & 2.212 & 1.145 & 309 & 0 \\
\hline $\begin{array}{l}\text { Sertão } \\
\text { Central }\end{array}$ & $\mathrm{N}^{\circ}$ de atendimentos & 4 & 1 & 0 & 506 & 484 & 526 & 160 & 43 \\
\hline $\begin{array}{l}\text { Cabugi e } \\
\text { Litoral Norte }\end{array}$ & $\begin{array}{l}N^{\circ} \text { de famílias } \\
\text { beneficiadas }\end{array}$ & 1 & 1 & 0 & 332 & 227 & 218 & 23 & 22 \\
\hline \multicolumn{2}{|c|}{ Total de atendimentos } & 5.012 & 1.752 & 6.337 & 13.130 & 13.397 & 6.584 & 4.500 & 791 \\
\hline \multicolumn{2}{|c|}{ Total de famílias beneficiadas } & 1.344 & 939 & 2.220 & 3.414 & 3.083 & 1.959 & 858 & 308 \\
\hline
\end{tabular}

Fonte: Elaborada pelos autores a partir do Painel de Monitoramento de Políticas das Secretaria Especial de Agricultura Familiar e do Desenvolvimento Agrário (2019).

Os dados da Tabela 7 mostram que o período de 2013 a 2016 foi o que mais registrou atendimentos de ATER nos territórios rurais, destacando-se o território do Mato Grande que recebeu a maior parte das ações realizadas nesse período. Como mencionado, o crédito e a assistência técnica são dois dos pilares para viabilização e fortalecimento do setor agrícola familiar. Neste sentido, a Tabela 8 expõe os dados do PNAE.

Tabela 8 - Dados da aquisição da agricultura familiar para a alimentação escolar (PNAE).

\begin{tabular}{|c|c|c|c|c|}
\hline \multirow[b]{2}{*}{ Ano } & \multirow[b]{2}{*}{ PNAE } & \multicolumn{3}{|c|}{ Território } \\
\hline & & Açu-Mossoró & Mato Grande & $\begin{array}{c}\text { Sertão Central } \\
\text { Cabugi e Litoral } \\
\text { Norte }\end{array}$ \\
\hline \multirow[t]{3}{*}{2011} & Valor transferido FNDE $(\mathrm{R} \$)$ & $4.414 .680,00$ & $3.043 .680,00$ & $1.041 .300,00$ \\
\hline & Valor comprado da AF (R\$) & $694.312,83$ & $221.667,06$ & $58.205,10$ \\
\hline & $\% A F$ & $15,7 \%$ & $7,3 \%$ & $5,6 \%$ \\
\hline \multirow[t]{3}{*}{2012} & Valor transferido FNDE (R\$) & $5.323 .716,00$ & $3.991 .788,00$ & $1.287 .840,00$ \\
\hline & Valor comprado da AF (R\$) & $1.113 .344,92$ & $303.178,77$ & $94.183,82$ \\
\hline & $\% A F$ & $20,9 \%$ & $7,6 \%$ & $7,3 \%$ \\
\hline \multirow[t]{3}{*}{2013} & Valor transferido FNDE (R\$) & $6.124 .944,00$ & $4.450 .014,00$ & $1.342 .702,00$ \\
\hline & Valor comprado da AF & $1.140 .586,65$ & $932.842,93$ & $90.447,42$ \\
\hline & $\% A F$ & $18,6 \%$ & $21,0 \%$ & $6,7 \%$ \\
\hline \multirow[t]{3}{*}{2014} & Valor transferido FNDE (R\$) & $5.750 .220,00$ & $4.110 .854,00$ & $981.408,00$ \\
\hline & Valor comprado da AF ( $\mathrm{R} \$)$ & $1.184 .241,08$ & $931.810,20$ & $121.032,30$ \\
\hline & $\% \mathrm{AF}$ & $20,6 \%$ & $22,7 \%$ & $12,3 \%$ \\
\hline
\end{tabular}

Fonte: Elaborada pelos autores a partir do FNDE/PNAE (Brasil, 2019). 
Tabela 8 - Continuação...

\begin{tabular}{ccccc} 
& & \multicolumn{3}{c}{ Território } \\
\cline { 3 - 5 } Ano & PNAE & Açu-Mossoró & Mato Grande & $\begin{array}{c}\text { Sertão Central } \\
\text { Cabugi e Litoral } \\
\text { Norte }\end{array}$ \\
\cline { 3 - 5 } 2015 & Valor transferido FNDE (R\$) & $6.478 .266,00$ & $4.590 .148,40$ & $1.630 .532,00$ \\
& Valor comprado da AF (R\$) & $1.507 .605,35$ & $781.546,69$ & $85.425,29$ \\
\multirow{2}{*}{2016 AF } & $23,3 \%$ & $17,0 \%$ & $5,2 \%$ \\
\cline { 3 - 5 } 2017 & Valor transferido FNDE (R\$) & $5.936 .042,63$ & $4.404 .723,86$ & $1.664 .393,05$ \\
& Valor comprado da AF (R\$) & $1.397 .880,19$ & $830.558,65$ & $94.157,53$ \\
& Valor AF & $23,5 \%$ & $18,9 \%$ & $5,7 \%$ \\
& Valor comprado da AF (R\$) & $6.246 .034,40$ & $2.330 .273,00$ & $1.526 .658,40$ \\
& \% AF & $671.741,54$ & $468.290,39$ & $107.859,84$ \\
\hline
\end{tabular}

Fonte: Elaborada pelos autores a partir do FNDE/PNAE (Brasil, 2019).

Como visto anteriormente, a partir do ano de 2009, entrou em vigor a Lei $n^{\circ} 11.947$, a qual estabelece que 30\% do valor repassado pelo PNAE deve ser investido na compra direta de produtos da agricultura familiar. Entretanto, analisando os dados da Tabela 8, verifica-se que os percentuais de aquisição de produtos da agricultura familiar estão abaixo da meta para os territórios avaliados. Ressaltando que o território Sertão Central Cabugi e Litoral Norte é o que apresenta menor participação, ficando abaixo de 10\% para o período, com exceção do ano de 2014, quando a proporção verificada foi de 12,3\%. Não obstante, esse é o território com menor quantidade de agricultores familiares com DAPs ativas, é o que tem acesso à menor parcela de projetos e de crédito do PRONAF, além de apresentar uma grande concentração de terras, conforme destacado em análises anteriores. Para os territórios Açu-Mossoró e Mato Grande, verifica-se que, mesmo com a quantidade de agricultores com DAPs ativas e com maior acesso aos recursos do PRONAF, a meta ainda não foi atingida. Assim, ainda há espaço para a expansão do fornecimento para o PNAE, visto que o maior percentual apresentado no período para o território Açu-Mossoró foi de 23,5\% (2016) e, para o território Mato Grande, foi de 22,7\% (2014).

Esse eixo de análise que trata da construção de mercados pela agricultura familiar também foi objeto das entrevistas realizadas, a fim de entender como as cooperativas têm se articulado no intuito de construir e acessar mercados. O quadro 5 apresenta os excertos das entrevistas no tocante a esse eixo de análise.

Quadro 5 - Eixo de construção de mercados.

\begin{tabular}{|c|c|}
\hline Territórios & Excertos das entrevistas \\
\hline Açu-Mossoró & $\begin{array}{l}\text { COOAFAM (Mossoró): "Antes a gente não conseguia ver a importância que tinha uma cooperativa na } \\
\text { vida de um agricultor, hoje, } 5 \text { anos à frente de uma, é que eu vejo. [...] ... é como que a cooperativa, } \\
\text { ela é os olhos do agricultor, ela tem mais acesso à informação. [...] A cooperativa hoje é algo de } \\
\text { fundamental importância para que a agricultura familiar caminhe. [Receita } 100 \% \text { do mercado } \\
\text { institucional] } \\
\text { [...] quando falam em energia solar, em energias renováveis, eu acho que os meus olhos brilham, } \\
\text { porque eu vejo sim uma grande porta, algo bom pra agricultura familiar, um grande casamento. [...] } \\
\text { hoje o principal fator limitador de acesso às energias renováveis é crédito." } \\
\text { cooperCAJU (Serra do Mel): "A cooperativa, hoje nós temos alguns sócios pagando um preço muito } \\
\text { alto por não acreditar, por não se firmar como um bom sócio na cooperativa. [...] não vejo mercado } \\
\text { como problema, vejo problema em organização, em a gente organizar a cooperativa pra chegar no } \\
\text { mercado." }\end{array}$ \\
\hline
\end{tabular}

Fonte: Pesquisa de campo. 
Quadro 5 - Continuação...

\begin{tabular}{|c|c|}
\hline Territórios & Excertos das entrevistas \\
\hline Mato Grande & $\begin{array}{l}\text { COOAFES (João Câmara): "A cooperativa é fundamental em todo o contexto, desde a produção } \\
\text { até chegar no mercado. [...] A nível municipal, a gente acessa as feiras locais, mas, de uma maneira } \\
\text { pontual, é mais organizado na CECAFES, [...]conquistamos esse espaço aqui nessa parceria com a } \\
\text { AFURN. Nós já estamos no mercado aberto e estamos nos organizando para voltar para o mercado } \\
\text { institucional. Que são duas opções importantes para escoar a produção da agricultura familiar do } \\
\text { Mato Grande. [Receita 100\% do mercado aberto] } \\
\text { [...] Vejo a agregação das energias renováveis à agricultura familiar como uma possibilidade de futuro, } \\
\text { de médio prazo, a gente ainda vai sofrer um pouquinho na energia convencional né? Mas vamos } \\
\text { buscar. [...] o principal fator limitador seria financiamento, financiamento de equipamentos." }\end{array}$ \\
\hline $\begin{array}{l}\text { Sertão Central } \\
\text { Cabugi e } \\
\text { Litoral Norte }\end{array}$ & $\begin{array}{l}\text { COOPP (Pedra Preta): "[...]hoje nós temos vários mercados, nós temos o mercado institucional e } \\
\text { o não institucional, acaba que nós ainda estamos muito presos na questão de organizar a cadeia } \\
\text { produtiva. [...] é uma cultura que nós estamos tentando criar na nossa região. } \\
\text { [...] agora de inicial eu não consigo associar essa questão da energia renovável com a ampliação } \\
\text { dos mercados, pode até ser que no desenrolar da execução dos projetos de maneira gradativa, a } \\
\text { gente consiga visualizar mais uma conexão, mas hoje eu não visualizo. [...] como principal fator de } \\
\text { limitação do acesso a energias renováveis eu vejo as linhas de financiamento que não são destinadas à } \\
\text { cooperativa, elas são destinadas mais a produtores[...]" }\end{array}$ \\
\hline
\end{tabular}

Fonte: Pesquisa de campo.

Observa-se, pelos excertos apresentados, que a questão da construção de mercados é decisiva para a manutenção da produção agrícola familiar. Nota-se que o mercado se divide basicamente em duas vertentes, o mercado institucional e o mercado aberto. As cooperativas são uma forma de organização coletiva que fortalecem os pequenos agricultores e dão acesso à capacitação e informação que eles não teriam, caso atuassem isoladamente, como destacado pela COOAFAM. Essa dificuldade de organização coletiva prejudica toda a cadeia produtiva, como é o caso da COOPERCAJU.

Outro fator importante, verificado através das entrevistas, é que, além de construir mercados, é preciso pensar na capacidade produtiva dos agricultores associados. Com relação às energias renováveis, todos compartilham da opinião de que é algo interessante para a agricultura familiar, sendo que uns já conseguem fazer essa associação no curto prazo, ou seja, já veem essa possibilidade, como é o caso da COOFAM, e os outros enxergam essa possibilidade, mas para o médio prazo. Independentemente disso, é unânime que a principal barreira para acesso às energias renováveis pela agricultura familiar trata-se de crédito.

\section{Considerações finais}

A pesquisa que dá guarida a este artigo foi elaborada tomando como base a perspectiva do Nexus entre agricultura familiar, energias renováveis e construção de mercados, aplicada a um recorte territorial no Estado do Rio Grande do Norte, que incluiu os territórios Açu-Mossoró, Mato Grande e Sertão Central Cabugi e Litoral Norte, principais produtores de energia eólica no Estado.

Foi possível verificar que o território Açu-Mossoró tem grande influência econômica no Estado e, dentre os territórios avaliados, além de apresentar a maior extensão de área destinada à agropecuária, concentra o maior número de trabalhadores empregados, sendo que as atividades da agricultura familiar tendem a se organizar coletivamente, dada a quantidade de cooperativas de agricultores familiares deste território. O território do Mato Grande também apresenta grande importância para o Estado do Rio Grande do Norte, principalmente no que se refere à produção de alimentos, e se caracteriza pela organização coletiva dentro da agricultura familiar, sendo o território, dentre os avaliados, que apresentou o maior número 
de associações/cooperativas com DAPs. Já no território Sertão Central Cabugi e Litoral Norte observou-se que é onde a agricultura familiar apresenta ainda mais fragilidades. Além da dificuldade de organização coletiva, a cadeia produtiva é muito específica, necessitando ampliar a diversidade na produção de alimentos pelos pequenos produtores.

Os dados analisados demostram que atualmente o Rio Grande do Norte é o maior produtor de energia eólica dentre os estados brasileiros, sendo que os territórios avaliados representam 89\% da produção de energia eólica no Estado, com destaque para o território do Mato Grande que, sozinho, detém $68 \%$ de participação. Como observado, nesses territórios, a atividade agrícola familiar tem importância, se não em termos de representatividade no PIB, mas de geração de oportunidades no meio rural, além da contribuição para a segurança alimentar. Deste modo, como as áreas mais afetadas pela instalação dos parques eólicos são rurais, buscou-se compreender o cenário que vem se desenhando no Rio Grande do Norte e qual a relação com a agricultura familiar, especialmente as cooperativas, estabelecendo assim uma das perspectivas no Nexus.

Verificou-se que não há uma relação direta entre a agricultura familiar e energias renováveis, no que se refere ao consumo da energia gerada, dado que as áreas rurais apresentam baixo consumo de eletricidade. As usinas eólicas instaladas no território analisado possuem alta capacidade de geração e estão conectadas diretamente ao sistema interligado nacional (SIN), por meio de subestações, podendo, portanto, ser consumida em qualquer região do país que esteja dentro desse sistema. Porém foram encontradas relações indiretas, como a de que a implantação de parques eólicos em propriedades de agricultores familiares tem gerado renda não agrícola proveniente de royalties de arrendamento de suas terras para a produção de energia eólica, e isso persistirá por um período bastante prolongado, cerca de 20 a 30 anos, de acordo com os contratos firmados, os quais são sigilosos e variam conforme a empresa e com a produção de energia, sendo cerca $\mathrm{R} \$ 1.300$ por mês o valor médio pago por cada aerogerador. A renda por família decorrente dessa atividade depende da quantidade de torres instaladas em sua propriedade.

Com base nesta análise, é possível expor duas hipóteses mutuamente excludentes: uma de que os agricultores familiares podem estar utilizando a renda não agrícola para investir nas suas terras; o que leva a crer em uma potencial ampliação da capacidade produtiva. A outra, é de que essa capacidade de produção também pode ser reduzida pela impossibilidade de acesso às terras arrendadas, sendo que, no caso do agricultor familiar, esse impacto poderia ser ainda maior, dadas as pequenas áreas das suas propriedades comparadas às dos grandes produtores (não familiares). Esta constatação sugere a necessidade de investigações posteriores para apurar se a inovação da geração de energia eólica nos territórios da AF do RN corre o risco de se encaminhar para a mesma direção do petróleo, que gera royalties expressivos, mas a riqueza gerada não se esparrama (efeito trickle down) para as economias locais e nem beneficia os pequenos produtores.

Nestes termos, é possível afirmar que há uma relação entre agricultura familiar e energias renováveis dos parques eólicos instalados no Rio Grande do Norte, que se dá pela internalização dessas tecnologias através da implantação de sistemas de autogeração nas propriedades, que tendem a desenvolver atividades de baixo carbono. Como exemplo pode-se citar o caso observado no projeto "Quintais Irrigados" onde, de acordo com a COOAFAM, a capacidade produtiva dos agricultores familiares que possuem o sistema de geração de energia solar fotovoltaica, possibilitou a utilização de sistemas de irrigação em áreas onde antes esse processo era realizado de forma manual. 
Com base na abordagem do Nexus, constatou-se que as cooperativas de agricultores familiares são instrumentos fundamentais para garantir o acesso a mercados, tanto o aberto (privado) quanto os institucionais, especialmente por meio do PAA e do PNAE. Ademais, tem-se, nesse modelo de organização coletiva das cooperativas, a possibilidade de acesso a políticas públicas que se tornam inviáveis caso o agricultor continue atuando isoladamente, além da capacitação técnica e o acesso a informações que podem contribuir para o desenvolvimento de atividades de baixo carbono em suas localidades.

Deste modo, verificou-se que a abordagem do Nexus traz uma contribuição importante que permite estabelecer análises integradas e relacionadas. Malgrado termos identificando relações tênues, percebe-se que o desenvolvimento regional no RN tem sido influenciado pela expansão da produção de energia eólica e que esse crescimento tem impactos na dinâmica econômica e social da atividade agrícola familiar, que por sua vez (do lado da demanda) possibilita a inserção e o aumento da participação da agricultura familiar em mercados institucionais e privados. Neste aspecto, é preciso ressaltar que a organização coletiva, por meio das cooperativas, é um fator de grande relevância, dado que o acesso às políticas públicas se dá por meio de instituições formais.

Por fim, é importante destacar a indução do Estado como categoria fundante do Nexus. A conexão entre energias renováveis, mercados institucionais, mercados privados e agricultura familiar não existiria sem o Estado. O Estado é categoria-chave dessa discussão, como evento inicial impulsionador dos demais processos. As políticas públicas implementadas tanto como fonte de incentivo para proporcionar a diversificação da matriz energética nacional, através do PROINFA, quanto para ampliação dos mercados institucionais como os programas governamentais (PAA, PNAE). Não é mão invisível do mercado que cria as condições iniciais para a implantação dos projetos eólicos. É o Estado quem o faz, na geração de mercados institucionais para os agricultores familiares, mediante pagamento de royalties por arredamento de terras, criando as condições iniciais e, depois, os projetos privados de geração dessa própria energia, fortalecendo essa cadeia produtiva.

\section{Referências}

Agência Nacional de Energia Elétrica - ANEEL. (2015). Proinfa. Recuperado em 01 de junho de 2019, de https://www.aneel.gov.br/proinfa

Agência Nacional de Energia Elétrica - ANEEL. (2019). Banco de Informações de Geração. Recuperado em 04 de agosto de 2019, de http://www2.aneel.gov.br/aplicacoes/ capacidadebrasil/capacidadebrasil.cfm

Banco Nacional de Desenvolvimento Econômico e Social - BNDES. (2018). PronafEco. Recuperado em 25 de março de 2020, de https://www.bndes.gov.br/SiteBNDES/bndes/bndes_pt/Galerias/ Convivencia/Restauracao_Ecologica/linhas_financiamento.html

Bermann, C. (2008). Crise ambiental e as energias renováveis. Ciência e Cultura, 60(3), 20-29. Recuperado em 18 de abril de 2019, de http://cienciaecultura.bvs.br/scielo.php?script=sci_ar ttext\&pid=S0009-67252008000300010

Borelli, E. (2018). Economia política da água no Brasil. In A. Kon \& E. Borelli (Org.), Economia brasileira em debate: subsídio ao desenvo/vimento (pp. 277-293). São Paulo: Blucher.

Brasil. (2002, 26 abril). Lei no 10.438, de 26 de abril de 2002. Programa de Incentivo às Fontes Alternativas de Energia Elétrica (Proinfa). Recuperado em 18 de abril de 2019, de: http:// www.planalto.gov.br/ccivil_03/leis/2002/110438.htm 
Secretaria Especial de Agricultura Familiar e do Desenvolvimento Agrário. (2019). DAP. Recuperado em 02 de agosto de 2019, de http://www.mda.gov.br/sitemda/dap/faq

Brasil. (2019). FNDE/PNAE - Dados da aquisição da agricultura familiar para a alimentação escolar. Recuperado em 02 de agosto de 2018, de https://www.fnde.gov.br/programas/ pnae/pnae-consultas/pnae-dados-da-agricultura-familiar

Brasil. Ministério de Minas e Energia. (2020). Programa Nacional de Produção e Uso do Biodiesel. Recuperado em 20 de outubro de 2020, de http://www.mme.gov.br/web/guest/secretarias/ petroleo-gas-natural-e-biocombustiveis/acoes-e-programas/programas/biodiesel/sobreo-pnpb.

Brasil. Secretaria Especial do Desenvolvimento Social. (2018). PAA - Programa de Aquisição de Alimentos. Recuperado em 02 de outubro de 2018, de http://mds.gov.br/assuntos/ seguranca-alimentar/programa-de-aquisicao-de-alimentos-paa

Campos, M. S., \& De Alcantara, L. D. S. (2018). Sistema de bombeamento fotovoltaico para irrigação na agricultura familiar. Brazilian Journal of Animal and Environmental Research, 1(1), 205-214. Recuperado em 23 de outubro de 2020, de https://www.brazilianjournals. com/index.php/BJAER/article/view/742.

Companhia Energética do Rio Grande do Norte - Cosern. (2003). Potencial eólico do Rio Grande do Norte. Recuperado em 30 de março de 2019, de http://www.cresesb.cepel.br/publicacoes/ download/atlas_eolico/atlas_eolico_RN.pdf.

Da Silva, C. C., \& Polli, S. A. (2020). O programa nacional de produção e uso do biodiesel-PNPB e a atuação da agricultura familiar. Brazilian Journal of Health Review, 3(2), 3542-3555.

Eletrobrás. (2018). Proinfa. Recuperado em 01 de junho de 2019, de https://eletrobras.com/ pt/Paginas/Proinfa.aspx

Embrapa. (2018). Visão 2030: O futuro da agricultura brasileira. Brasília, DF: Embrapa. Recuperado em 30 de junho de 2018, de https://www.embrapa.br/documents/10180/9543845/ Vis\%C3\%A3o+2030+-+o+futuro+da+agricultura+brasileira/2a9a0f27-0ead-991a-8cbfaf8e89d62829?version=1.1

EPE. (2019). Web Map Empresa de Pesquisa Energética. Recuperado em 21 de abril de 2019, de https://gisepeprd2.epe.gov.br/WebMapEPE/.

Federal Ministry for Economic Cooperation and Development - BMZ. (2015). Nexus. Recuperado em 10 de junho de 2018, de https://www.water-energy-food.org/uploads/media/nexusrealising-the-nexus_August_2015-schwarz.pdf

Flammini, A., Puri, M., Plushke, L., \& Dubois, O. (2017). Walking the Nexus talk: Assessing the water-energy-food Nexus in the context of the sustainable energy for all initiative. Rome, Italy: FAO.

Freitas, V. F., Polycarpo, R. C., Santos, A. L. S. A., \& Silva, L. B. (2017) Participação da agricultura Familiar no Programa Nacional de Produção e uso do Biodiesel (PNPB) no período de 2008 a 2015. Desenvolvimento Socioeconômico em Debate, 3(2), 59-80. Recuperado em 20 de outubro de 2020, de http://periodicos.unesc.net/RDSD/article/view/4044

Geels, F. W. (2014). Regime resistance against low-carbon transitions: Introducing politics and power into the multi-level perspective. Theory, Culture \& Society, 31(5), 21-40. http://dx.doi. org/10.1177/0263276414531627

Instituto Brasileiro de Geografia e Estatística - IBGE/SIDRA. (2017)- Censo agropecuário 2017. Recuperado em 05 de novembro de 2020, de http://www.ibge.gov.br 
International Renewable Energy Agency - IRENA. (2015). Renewable Energy in the Water, Energy \& Food Nexus. Recuperado em 10 de junho de 2018, de https://www.irena.org/ documentdownloads/publications/irena_water_energy_food_nexus_2015.pdf

Losekann, L., \& Hallack, M. (2018). Novas energias renováveis no Brasil: desafios e oportunidades. In: J. A. Negri, B. C. Araújo \& R. Bacelette (Org.), Desafios da Nação: Artigos de apoio. Brasília: IPEA. Recuperado em 20 de abril de 2019, de http://repositorio.ipea.gov.br/ bitstream/11058/8446/1/Novas\%20energias\%20renov\%c3\%a1veis\%20no\%20Brasil_ desafios\%20e\%20oportunidades.pdf.

Maluf, R. S. (2004). Mercados agroalimentares e a agricultura familiar no Brasil: agregação de valor, cadeias integradas e circuitos regionais. Ensaios FEE, 25(1), 299-322. Recuperado em 19 de novembro de 2018, de https://revistas.fee.tche.br/index.php/ensaios/article/ viewFile/2061/2443

Marsden, T. K., \& Rucinska, K. (2019). After COP21: Contested transitions in the Energy/Agriculture Food Nexus. Sustainability, (March), 2019.

Nunes, E. M., \& Schneider, S. (2013). Reestruturação Agrícola, Instituições e Desenvolvimento Rural no Nordeste: a diversificação da agricultura familiar do Polo Açu-Mossoró (RN). Revista Economica do Nordeste, 44, 601-626.

Nunes, E. M., de Morais, A. C., de Aquino, J. R., \& Gurgel, I. A. (2018). O Programa Nacional de Alimentação Escolar (PNAE) como mecanismo de política de inclusão na agricultura familiar do Nordeste do Brasil. Revista Grifos, 27, 114-139.

Nunes, E. M., Tôrres, F. L., Silva, M. R. F.; Sá, V. C., \& Godeiro, K. F. (2015). Dinamização Econômica e Agricultura Familiar: limites e desafios do apoio a Projetos de Infraestrutura (Proinf) em territórios rurais do Nordeste. Revista de Economia e Sociologia Rural, 53, 529-554.

Paranhos, B. R., Da Silva, F. C., \& Cataldi, M. (2017). A energia eólica como alternativa energética para agricultura familiar em regiões serranas. Ciência e Natura, 39(1), 193-201. Recuperado em 23 de outubro de 2020, de https://www.redalyc.org/pdf/4675/467549116021.pdf.

Rambo, A. G., Filippi, E. E., \& Lima, S. K. (2008, julho 20-23). Desenvolvimento territorial: programa nacional de produção e uso do biodiesel x projeto microdestilarias. In Anais do $46^{\circ}$ Congresso da Sociedade Brasileira de Economia, Administração e Sociologia Rural. Rio Branco: SOBER. Recuperado em 20 de outubro de 2020, de www.ufrgs.br/pgdr/publicacoes/ producaotextual/eduardo-ernesto-filippi/rambo-a-g-filippi-e-e-lima-s-k-desenvolvimentoterritorial-programa-nacional-de-producao-e-uso-do-biodiesel-x-projeto-microdestilariasin-xlvi-congresso-da-sociedade-brasileira-de-economia-administracao-e-sociologia-ruralsober-amazonia-mudancas-globais-e.

Rodrigues, T. P., Gonçalves, S. L., \& Chagas, A. L. S. (2016). Usinas eólicas e o mercado de trabalho nos municípios do Nordeste brasileiro. In 6th Latin American Energy Economics Meeting. Recuperado em 23 de março de 2020, de https://www.anpec.org.br/encontro/2016/ submissao/files_1/i10-d8cc205ee197d4af658822148a2874e7.pdf.

Sachs, I. (2007). Integração dos agricultores familiares e dos empreendedores de pequeno porte na produção dos biocombustíveis. In: Anais do Workshop da Fundação Brasileira do Desenvolvimento Sustentável, Rio de Janeiro: Fundação Brasileira para o Desenvolvimento Sustentável.

Santos, G. R. (2014). Infraestrutura de pesquisa em energias renováveis no Brasil. Boletim Radar - Tecnologia, Produção e Comércio Exterior, 35, 7-18. Disponível em: http://repositorio. ipea.gov.br/bitstream/11058/3949/1/Radar_n35_infraestrutura.pdf 
Secretaria de Estado do Planejamento e das Finanças. (2016). Diagnóstico consolidado. Recuperado em 18 abril de 2019, de http://www.rnsustentavel.rn.gov.br/smiv3/site/conteudos/midias/ f4d69d8f19e0f0eb25865c75235bfb77.pdf.

Secretaria de Estado do Planejamento e das Finanças - SEPLAN. (2013). Relatório de Identificação e Mapeamento das Aglomerações Produtivas do Estado do Rio Grande do Norte. Recuperado em 30 de julho de 2019, de http://www.rnsustentavel.rn.gov.br/smiv3/site/documentos/ arquivo/ea5d60a4d9131854276cc5d9177c599c.pdf

Secretaria Especial de Agricultura Familiar e do Desenvolvimento Agrário - SEAD. (2019). Painel de Políticas da Sead. Recuperado em 01 de agosto de 2019, de http://nead.mda.gov.br/ politicas.

Serraj, R., \& Pingali, P. (2018). Agriculture \& Food Systems to 2050: Global Trends, Challenges and Opportunities. World Scientific. https://doi.org/10.1142/11212.

Sistema de Informações Territoriais - SIT. PTDRS. (2010). Plano Territorial de Desenvolvimento Rural Sustentável. Recuperado em 30 maio de 2018, de http://sit.mda.gov.br/download.php..

Tilman, D., Socolow, R., Foley, J. A., Hill, J., Larson, E., Lynd, L., Pacala, S., Reilly, J., Searchinger, T., Somerville, C., \& Williams, R. (2009) Beneficial biofuels-The food, energy, and environment trilemma. Science, 325(5938), 270-271. Recuperado em 20 de março de 2020, de https://www. researchgate.net/profile/Robert_Socolow/publication/237285820_Benefi_cial_BiofuelsThe_ Food_Energy_and_Environment_Trilemma/links/0c96052836d1 fe3735000000/Benefi-cialBiofuelsThe-Food-Energy-and-Environment-Trilemma.pdf

Urry, J. (2014). The problem of energy. Theory, Culture \& Society, 31(5), 3-20. Recuperado em 25 de março de 2020, de http://citeseerx.ist.psu.edu/viewdoc/download?doi=10.1.1.928. 8459\&rep=rep $1 \&$ type $=$ pdf

Zanella, M. E. (2014). Considerações sobre o clima e os recursos hídricos do semiárido nordestino. Caderno Prudentino de Geografia, 36, 126-142. 